\title{
Physical Climate Change and the Sovereign Risk of Emerging Economies
}

\author{
Hannes Boehm* \\ Halle Institute for Economic Research (IWH) \\ TU Dresden
}

First Version: June 2020

This Version: September 2021

\begin{abstract}
I show that rising temperatures can detrimentally affect the sovereign creditworthiness of emerging economies. To this end, I collect long-term monthly temperature data of 54 emerging markets. I calculate a country's temperature deviation from its historical average, which approximates present-day climate change trends. Running regressions from 1994m1-2018m12, I find that higher temperature anomalies lower sovereign bond performances (i.e. increase sovereign risk) significantly for countries that are warmer on average and have lower seasonality. The estimated magnitudes suggest that affected countries likely face significant increases in their sovereign borrowing costs if temperatures continue to rise due to climate change. However, results indicate that stronger institutions can make a country more resilient towards temperature shocks, which holds independent of a country's climate.
\end{abstract}

Keywords: Climate Risks, Sovereign Risk, International Finance, Emerging Market Economies, Institutions

JEL Classification: Q54, Q56, G15, H63, O13

*hannes_boehm@hotmail.de; Please find here the online appendix of this paper. A short version of this article was published on the Principles for Responsible Investments Blog. I am grateful for all the advice I received for this project, in particular from Stefan Eichler, Felix Noth, Thomas Krause, Ingmar Roevekamp, Christoph Schult, Gregor von Schweinitz, Lena Tonzer and Konstantin Wagner. Special thanks goes to Michael Barkholz for helping on temperature data and Mikael Homanen's literature review on ESG \& finance. All errors are my own. 


\section{Introduction}

As of 2020 , human activities are estimated to have caused approximately $1.0^{\circ} \mathrm{C}$ of global heating compared to pre-industrial levels (IPCC 2018). Climate-related natural disasters, infectious diseases, species extinction and threats to economic prosperity as well as food, health and water supply are projected to increase dramatically with further warming. However, the IPCC (2018) also emphasizes that the $1.0^{\circ} \mathrm{C}$ increase witnessed so far has already led to more extreme weather events, changing natural systems and economic damages. Furthermore, the report states that the burden of climate change will be particularly heavy for developing countries in the global South.

In this paper, I exploit temperature fluctuations of past years which represent physical climate change risks in line with the $1.0^{\circ} \mathrm{C}$ heating witnessed so far. I contribute to the literature by linking these movements in temperature to the sovereign creditworthiness of, potentially climate-vulnerable, emerging market economies. Though the literature on the economic effects of temperature fluctuations is rich, the link to sovereign bond performances or sovereign risk has so far been missing.

Despite this gap in the literature, climate change can pose a significant threat for the creditworthiness of sovereigns according to several regulatory bodies. For instance, a report on the financial risks from climate change by the Bank of England (2018) states:
"The increasing frequency of severe weather events could also impact macroeco- nomic conditions through sustained damage to national infrastructure and weaken fundamental factors such as economic growth, employment, and inflation. This could have implications for the market price of sovereign debt for those countries most susceptible to the physical impacts of climate change." 1

Furthermore, rating agencies such as Moody's (2016) have started incorporating the credit implications of climate change for sovereign issuers. ${ }^{2}$ These developments matter, as sovereign creditworthiness and associated bond costs are crucial for all governments. Rising borrowing costs compensate bondholders for higher risks, but can also push countries into crisis and

\footnotetext{
${ }^{1}$ Similar remarks can be found by the ECB (2019), stating: "sovereign risks could increase for countries with carbon-intensive industries."

${ }^{2}$ Moreover, governments are increasingly facing legal consequences for not disclosing climate risks in their sovereign bond disclosures, as described in a Bloomberg article from 22 June 2020: "Australia Sued For Not Disclosing Climate Risk in Sovereign Debt"
} 
default. Even in the absence of debt crises, any unit of currency that is spent on borrowing costs can no longer be used for other expenditures such as adaptions to climate change.

Therefore, I extend the literature on climate risks, in the form of temperature fluctuations, in connection with financial markets, in the form of sovereign bond returns. Figure 1 illustrates the main idea of my empirical approach. It depicts the mean annual temperature of the 54 countries in my panel from 1901 to 2018, showing an upward trend since the second half of the 20th century. The red line shows the constant temperature average from 1901 to 1950. From 1994 onward, which is the start of my estimation period and the shaded area in the graph, I calculate a country's temperature deviation from its 1901-1950 average. This temperature anomaly variable has a mean of $0.84^{\circ} \mathrm{C}$, which is close to the global heating trend of $1^{\circ} \mathrm{C}$ estimated by the IPCC (2018).

- Figure 1 around here -

In my estimation, I follow the "new approach" outlined by Dell et al. (2014). Using monthly data for 54 emerging economies from 1994 to 2018, I regress market returns of the Emerging Market Bond Index (EMBI), a common measure for sovereign debt performance, on the described temperature anomaly fluctuations. I control for precipitation and include country and region-time fixed effects on the month-year level. The captured temperature shocks are thus idiosyncratic and account for weather trends common to each region. Building on a rich literature that links temperature increases to lower GDP growth in poorer and warmer countries (Burke et al. 2015, Dell et al. 2012), reduced firm productivity and output (Zhang et al. 2018, Adhvaryuy et al. 2019), decreasing labor supply (Graff Zivin \& Neidell 2014) and more interpersonal and civil conflict (Hsiang et al. 2013), I empirically test the hypothesis if rising temperatures compared to a country's historical temperature average lead to lower sovereign debt performance (i.e. increasing sovereign risk).

My results indicate that the effect of rising temperature anomalies on sovereign creditworthiness critically hinges on a country's economic and climatic profile: Warm countries are significantly more susceptible to temperature shocks than cold or mild-tempered countries, which is line with the results of Burke et al. (2015). For countries with very high average annual temperatures $\left(>25^{\circ} \mathrm{C}\right)$, a $1^{\circ} \mathrm{C}$ increase in monthly temperature compared to a country's historical average lowers EMBI returns by 0.464 percentage points on average. This effect corresponds to $11.9 \%$ of the EMBI returns' overall standard deviation. Thus, in a $2^{\circ} \mathrm{C}$ global 
heating scenario, EMBI returns (in percentage points) could be lowered for affected countries by roughly a quarter of their overall standard deviation. This magnitude is non-negligible and could lead to rising sovereign borrowing costs or even defaults for warmer countries in the next decades. Such out-of-sample projections must of course be treated carefully, as they abstain from countries' adaption strategies towards climate change but also from potentially non-linearly aggravating weather effects that are entailed by continuously rising temperatures (see Bolton et al. (2020)). However, if the past temperature anomaly shocks captured in this paper are any guidance, warm countries could bear a major burden from future temperature increases in the form of lower sovereign creditworthiness.

Following the analysis of a country's climatic profile, I test if different economic sector specializations could be related to the strength of temperature shocks on sovereign debt performance. To this end, I interact the temperature anomaly measure with the specialization of a country in terms of agriculture, manufacturing, services or natural resources. However, these specifications do not yield any statistical patterns indicating that countries with higher agricultural shares on GDP, more service sector employees or larger rents from natural resources such as oil are more (or less) susceptible to temperature shocks with respect to their sovereign risk. My results do not rule out that potentially stranded industries, such as fossil fuels, may affect sovereign debt prices in the future. Still, the effect seems to be weak during my estimation period or not connected to temperature shocks.

What instead holds remarkably well throughout the analysis is the conditioning impact of institutional quality on temperature-induced sovereign risk. Countries with weaker rule of law, control of corruption, civil rights, democratic governments or less progressive tax systems face a statistically significantly stronger marginal effect of temperature increases that is detrimental to their sovereign creditworthiness. Next to these more traditional institutional variables, climate-related metrics yield a similar conclusion: Countries with lower values in the ND-Gain index, which measures both the adaptiveness and vulnerability of a country towards climate change, face significantly higher temperature shock effects on their sovereign risk level. Disentangling the ND-Gain index reveals that this effect is driven more by the adaptive readiness than the vulnerability part of the index. In line with the recommendations of the IPCC (2018), these results suggest that higher overall institutional quality, both traditional 
and climate-related, could improve the resilience and adaptiveness of emerging economies towards climate change.

I also find evidence that poorer countries suffer more from temperature shocks. However, these factors are correlated as poorer countries tend to have worse institutions. In addition, it is difficult to disentangle the long-run effects of climate zones on the creation of institutions or the wealth of nations (see Acemoglu et al. (2002) for a discussion).

I shed some light on these interrelations by combining all relevant channels, i.e. warmness, poverty and institutional quality, in one regression. My evidence suggests that the effect of poorer countries suffering stronger from temperature shocks is indeed driven by these countries' tendencies to have worse institutions. However, both the institutional and the warmness channel remain statistically significant in the same specification, suggesting that stronger institutions can provide resilience towards temperature shocks, independent of the warmness of a country.

I conduct encompassing robustness tests to demonstrate the stability of my results. These procedures include changing the fixed effects specification and dependent variable of the baseline. I also drop certain countries from the analysis, firstly if they have few EMBI data points, secondly if their landmass is among the ten largest countries, thirdly if they experienced episodes of political instability. Further tests in the online appendix are on the lag structure, the historical average period of temperature shocks as well as different clustering and stationarity tests. The main results stay intact.

Lastly, I analyze potential underlying channels of the temperature-sovereign risk relationship. First, I provide evidence that heat-related natural disasters, such as droughts or wildfires, have stronger impact in harming the economic performance of the warmest countries. This finding provides an indication why warm countries are more susceptible to higher temperatures and is a promising avenue for future research. Second, I test if the temperature effects changed after the Paris Agreement in December 2015, which does not seem to be the case.

Though any further disentanglement of these channels is beyond the scope of this paper, what matters for the policy implications is the finding that countries with warmer weather and lower institutional quality have so far been hit significantly harder by temperature anomaly shocks with respect to their sovereign creditworthiness. This result is an important extension 
to the still young literature on climate risks and financial markets. If past trends are any guidance, affected countries could face meaningful increases in their sovereign debt costs or even debt crises as climate change intensifies.

The rest of the paper is structured as follows. Section 2 provides a framework on how to think about physical climate change risk and its relationship to sovereign risk. Section 3 introduces the data and provides summary statistics. Section 4 describes the empirical framework and main regression results. Section 5 investigates the climatic and economic profiles of countries and their relationship to temperature-induced sovereign risk. The subsequent Section 6 provides encompassing robustness checks. I test for possible underlying mechanisms of temperature shocks in Section 7. Section 8 concludes.

\section{Physical Climate Change Risk}

\subsection{Physical Climate Change Risk in Contrast to Transition Risk}

The following section provides a framework on how to think about climate change risks in a sovereign bond context. Table 1 by the Bank of England (2018) depicts the distinction between physical and transition risks as the two main channels of how climate change can lead to economic impairments.

- Table 1 around here -

Physical risks describe the materializing damages from climate change. They can arise from extreme weather events or natural disasters such as droughts, wildfires, sea level rises or floods. Regions hit by such disasters can face losses in terms of human lives, critical infrastructure, food supply, firm assets or their capital stock (see also Bolton et al. (2020)). As further global heating likely entails irreversible tipping points, these damages could lead to non-transitory, lasting disruptions (Ripple et al. 2019). According to the insurance data used by NGO Germanwatch (2019), the damages from extreme weather events worldwide between 1999 and 2018 amounted to $\$ 3.54$ trillion (in purchasing power parities). Physical climate risks can materialize as a mortgage risk for homeowners that lose their property, a credit risk for banks that lend to e.g. flood-impaired firms (Koetter et al. (2019)), an underwriting risk for insurance companies (Financial Stability Institute 2019) and, as demonstrated in this paper, 
a market risk for sovereigns bonds of countries most susceptible to the physical impacts of climate change.

In contrast, transition risks describe the adjustment towards a low-carbon economy and the expected damages and costs associated therewith. Therefore, these risks are more forward-looking as (expected) changes in environmental policies or sentiments could threaten, for instance, the business model of certain firms. Should investors reassess the viability of e.g. a fossil-energy-intensive industry as tougher climate laws are implemented, the stock price of affected firms might fall. Such a shock would likely spill-over to banks, pension funds and other investors with exposures towards stranded industries, which is referred to as a "carbon bubble" (see ESRB (2016) for an associated systemic risk analysis and Delis et al. (2018) for how banks price carbon bubble risks).

An example of transition risks in a government bond context that contrasts the physical risks in this paper is by Painter (2020). He shows that US municipalities that face stronger sea level increases in the future have higher issuance costs for their municipality bonds today. Because of its forward-looking nature, this effect demonstrates a transition risk. As projected climate damages from sea level increases rise over time, the results are driven by long-term bonds. In addition, the pricing effect increased around the release of the Stern report on climate change in 2006. Though not shown by Painter (2020), it could likely be the case that such re-pricing of climate-sensitive assets was even more pronounced in recent years as global heating became a major concern for the financial industry (see Boston Common Asset Management (2018) for a survey of global banks and Bolton \& Kacperczyk (2020) for asset pricing effects of firms' $\mathrm{CO} 2$ emissions).

In contrast to forward-looking transition risks, this paper, and the literature on temperature effects in general, analyze already materialized impacts of past temperature fluctuations. Temperature increases are associated with extreme weather events or hotter years and influence economic activities along several dimensions, as the next section demonstrates. Of course, both risk channels cannot be isolated completely from another: A wildfire might entail vast economic damages (physical risk), but also change perceptions of investors regarding the susceptibility of the affected region towards more wildfires in the future (transition risk). It is beyond the scope of this paper to disentangle these risk effects. Nevertheless, I will 
label temperature fluctuations as a form of physical risk in the following due to their primary impact on current economic activities.

\subsection{Physical Climate Change and Sovereign Creditworthiness}

Temperature fluctuations have economic effects that can likely spill-over to sovereign risk. Dell et al. (2012) show that higher temperatures reduce GDP growth of poorer countries. This effect is driven by lower agricultural and industrial value-added and increasing political instability during warmer years. Related, Burke et al. (2015) show that temperature has a non-linear effect on GDP growth, with warmer countries' economies being hit significantly more negatively by higher temperatures than colder or milder-tempered countries for which temperature increases are negligible or even beneficial. Heal \& Park (2014) and Deryugina \& Hsiang (2014) obtain similar results. Regarding the research agenda of this paper, it is likely that macroeconomic fundamentals like GDP growth or related fiscal conditions impact sovereign bond pricing (see Hilscher \& Nosbusch (2010) or Augustin \& Tédongap (2016)).

With respect to the microeconomic channels behind the temperature-GDP relationship, Zhang et al. (2018) find that more hot days per year in a Chinese region significantly reduce output and productivity of local firms. The authors derive that these effects could lower Chinese manufacturing output by $12 \%$ annually by 2050. Adhvaryuy et al. (2019), Cachon et al. (2012), Pankratz et al. (2019) and Somanathan et al. (2018) obtain similar evidence, confirming that labor becomes less productive with hotter days. In addition, Graff Zivin \& Neidell (2014) demonstrate that individual labor supply decreases with more warm days in a year. Pankratz \& Schiller (2019) show that climate shocks can negatively impact global production networks, while Kling et al. (2021) demonstrate that climate vulnerability can increase firms' debt costs. One notable exception to this micro evidence is by Addoum et al. (2020) who find weak effects of temperature shocks on US firm sales.

Climate and weather patterns also influence conflict and political stability. Hsiang et al. (2013) summarize in a meta-study several contributions that link increasing temperatures to more interpersonal conflict and crime, but also riots, civil conflict or ultimately civil war (see also Burke et al. (2009)). Sovereign bond yields are known to respond to political conditions (Eichler 2014) and it is highly plausible for temperature-induced political instability to increase sovereign risk. 
Though not every natural disaster can be directly linked to climate change, the IPCC (2018) projects climate-related disasters to increase with further global heating. Figure 2 depicts the total number of climate-related natural disasters such as floods, droughts and wildfires of the countries in my panel next to the average sample temperature from 1901 to 2018. There is a positive correlation between the rising occurrence of natural disasters and increasing temperature, however, this relationship is at least partially driven by better detection and recording of disasters. Nevertheless, the temperature anomaly measure in this paper picks up natural disasters to some extent, as shown in the next section, and it is intuitive to assume that severe disasters are detrimental to the economy and sovereign creditworthiness of a country (Felbermayr \& Gröschl 2014).

- Figure 2 around here -

As I use the market return of a financial asset as my dependent variable, it is worth noting that Bansal et al. (2016) demonstrate that most US equities have a negative exposure coefficient towards long-run temperature fluctuations. Temperature patterns and other climate-related measures are thus priced in financial assets (Bolton \& Kacperczyk 2020). In addition, corporate bonds that hedge against climate risks are associated with lower returns (Huynh \& Xia 2020).

The literature on the effects of temperature anomalies on sovereign creditworthiness is so far scarce, which is why this paper adds significant value to this debate. Next to cited work by Painter (2020), Klusak et al. (2021) study the effects of climate projections on sovereign ratings. Volz et al. (2020), Kling et al. (2018), Beirne et al. (2021b), Beirne et al. (2021a) and Cevik \& Jalles (2020) look at the relationship between sovereign borrowing costs and climate change more general. The authors regress bond costs on climate-related vulnerability metrics of countries, finding that more vulnerable countries pay higher debt costs. Though the specifics of the estimation strategy and the included countries differ, the results in my paper point in a similar direction. 


\section{$3 \quad$ Data and Descriptive Statistics}

\subsection{Sovereign Creditworthiness}

I measure sovereign creditworthiness using the Emerging Market Bond Index Global (EMBI) provided by J.P. Morgan. EMBI data has several advantages: Included sovereign bonds are U.S. Dollar-denominated, which rules out exchange rate risk. Eligible debt must furthermore have at least 2.5 years until maturity and only remains in the index until 12 months before it matures, so that maturity profiles are comparable. To ensure sufficient liquidity, only issues with an outstanding face value of at least $\$ 500$ million or more are considered for the index. These features make EMBI data well standardized, liquid and widely-used to track sovereign debt performances across emerging economies.

The start of the EMBI Global at the beginning of 1994 determines my estimation period, which runs from $1994 \mathrm{~m} 1$ to $2018 \mathrm{~m} 12$. While I adjust the panel composition as explained below, I start by collecting monthly EMBI Global data for all countries available. I then calculate month-to-month returns using natural log differences. Positive returns imply improving sovereign creditworthiness. ${ }^{3}$ I winsorize the returns at the 1 st and 99 th percentile to control for outliers.

To make sure that the panel consists of comparable countries with liquid data, I proceed in two steps. First, as some countries' EMBI series turn temporarily illiquid and hence constant in the index level, I drop all observations with a zero percent EMBI return. Second, to make sure every country in the sample has sufficient variation, I only include those countries with liquid EMBI returns of at least six years (72 months). This criterion is not critical for my results, as shown in a robustness test. This step reduces the final panel from nearly 70 to 54 countries. These countries can be found, together with region classifications from Dell et al. (2012), in Table 2. The panel is unbalanced because some countries enter only in later years. The robustness section contains further tests for the composition of the panel, in which I drop countries with lower data coverage, larger landmasses and countries that experienced severe political instability. The results are stable towards these changes.

- Table 2 around here -

\footnotetext{
${ }^{3}$ I obtain somewhat stronger results using direct EMBI returns. However, the results also hold when using EMBI spread data as shown in the robustness section. Since both measures are market returns, their interpretation, except for the switched signs, is very similar.
} 


\subsection{Temperature Data}

I obtain average monthly temperature data for every panel country since 1901 from the Climate Research Unit (CRU). The data is land-weighted and based on an extensive network of interpolated weather station data (see Harris et al. (2020) for details). ${ }^{4}$

My main variable of interest, as graphically depicted in Figure 1, measures the difference in the observed temperature of a country during 1994m1-2018m12 towards this country's 1901-1950 historical temperature average of that month:

$$
\text { HistoricalTempAnomaly }_{i t}=\text { Temperature }_{i t}-\text { TempAverage }_{i, t(1901-1950)}
$$

For instance, temperature in March of 2003 (year-month $t$ ) in Argentina (country $i$ ) is compared to the temperature of all months March of Argentina from 1901-1950.

This historical temperature anomaly is a proxy for the degree of global heating witnessed so far. Table 3 listing the summary statistics shows a corresponding mean of $0.842^{\circ} \mathrm{C}$ for the full sample period. This value approaches the $1^{\circ} \mathrm{C}$ temperature increase estimated by the IPCC (2018) compared to the pre-industrial age and lies well within their reported confidence range of $0.8^{\circ} \mathrm{C}$ to $1.2^{\circ} \mathrm{C}$. For the sample of temperature anomalies used in the main regressions, the mean is even at $0.896^{\circ} \mathrm{C}$. This rise is likely because several countries enter the estimation only in later years, when temperatures increased further.

In line with the assessment of the IPCC (2018) that the $1^{\circ} \mathrm{C}$ heating experienced so far has already led to impacts on natural and human systems and considering the evidence on the economic effects of temperature fluctuations gathered in Section 2, I interpret HistoricalTempAnomaly it $_{\text {as }}$ a measure for warmer than normal periods and extreme weather events. Some statistical confirmation for this perception comes from Table 4, showing that the mean of historical temperature anomalies is higher during periods of heat-related natural disasters such as droughts (0.898), droughts for which there is a damage estimate (0.946), wildfires (0.989) and heat waves $(0.988) .{ }^{5}$ In addition, I collect GDP growth, stock market and government primary surplus data, which is for the latter two variables only available for a subsample of countries. Table 4 shows that the overall mean of these economic conditions is differentiated during high and low temperature anomalies. For instance, the

\footnotetext{
${ }^{4}$ Data is freely available at: https://crudata.uea.ac.uk/cru/data/hrg/cru_ts_4.03/.

${ }^{5}$ Wildfires or heat waves with reported damages also have higher averages but low observations.
} 
mean of stock returns (overall: 0.233 ) is lower if temperature increases are above the 75 th percentile (-0.0478) and higher when temperature is below the 25th percentile (0.434). Similarly, primary surpluses (overall: -0.235) decrease during higher (-0.693) and rise during lower (0.400) temperature anomalies. Historical Temperature increases are thus responsive to both climate- and economy-related news. In addition, Section 7.1 shows more formally that natural disasters hurt a country's economic performance.

I include an additional temperature variable for the main regressions:

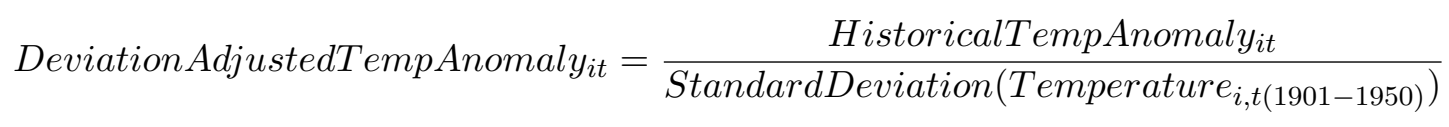

I divide the anomaly measure by a country's historical standard deviation of monthly temperature. This adjustment is suggested by Dell et al. (2014) and applied, among others, by Barrios et al. (2010). It sets the temperature shock in relation to the usual variation in warm- or coldness of a country. In this way, temperature anomalies in countries with lower seasonality, which correlates with warmer climate, are stronger emphasized. Definition and sources of all variables are in Table 18.

- Tables 3 and 4 around here -

\section{Empirical Specification and Results}

Following what Dell et al. (2014) call the "new approach", I estimate an OLS panel regression:

$\Delta$ SovereignCreditworthiness $_{i t}=\beta$ TemperatureAnomaly $y_{i t}+\delta$ Precip $_{i t}+\gamma_{i}+\gamma_{r t}+\epsilon_{i t}$

Natural log changes in the EMBI index ( $\Delta$ SovereignCreditworthiness $\left.{ }_{i t}\right)$ are regressed on a temperature anomaly measure and fixed effects. The sample runs from $1994 \mathrm{~m} 1$ to $2018 \mathrm{~m} 12$ and consists of 54 countries. Temperature anomalies are either the difference of temperature from its historical average (HistoricalTempAnomaly A $_{\text {) }}$ or the historical anomaly divided by monthly temperature standard deviation (DeviationAdjustedTempAnomalyit) as described in Section 3.2. The size and statistical significance of $\beta$ tests the hypothesis if and by how much temperature anomalies affect sovereign risk. Based on the gathered evidence in Section 2.2, I expect higher temperature anomalies leading to lower sovereign creditworthiness. 
I include country fixed effects $\gamma_{i}$ to control for time-invariant characteristics such as geography or culture. In addition, year-month fixed effects enter the regression and are interacted with the region classification of a country $\left(\gamma_{r t}\right)$. This approach, suggested among others by Dell et al. (2014), makes sure that common trends, such as shared weather patterns in each region, are controlled for. It ensures that captured temperature shocks are idiosyncratic and local in nature. I apply different fixed effects in the robustness section and find stable results.

Importantly, I do not include any control variables on the country level such as stock returns or exchange rates. This decision is due to the explicit stance of the temperature literature against including any control variable that might be endogenous towards weather and climate variation (Dell et al. (2014), Burke et al. (2015)). ${ }^{6}$ Given that stock returns are subject to similar temperature-productivity effects described in Section 2 and also unavailable on a liquid frequency for all panel countries, I abstain from including them. Following leading papers like Dell et al. (2012) and Burke et al. (2015), I only control for precipitation (Precip $p_{i t}$, also obtained from CRU) and include time-region fixed effects on the highest possible frequency (year-month). Standard errors are clustered on the country level.

Table 6 presents results from several versions of equation (3), including the baseline model. Column (1) introduces the historical temperature anomaly measure and both country and region-time fixed effects, but only on a yearly level. The temperature measure enters negative and statistically significant, but the overall explanatory power of the estimation is quite low. In column (2) I include precipitation on the country level and several international control variables such as changes in the VIX, the US term spread, US corporate risk spread, the 10year US treasury yield and the returns of a general government bond index. The temperature anomaly coefficient remains negative and statistically significant to this addition. Finally, I estimate the baseline model (column (3)) in which I introduce region times year-month fixed effects, which subsume all non-country specific controls. The explanatory power is now substantially larger, but the temperature anomaly measure is no longer statistically significant. This result might not be surprising, as the literature shows that only particularly affected countries respond to temperature shocks. ${ }^{7}$ Precipitation is statistically insignificant in the baseline and all following regressions.

\footnotetext{
${ }^{6}$ In their review article on climate and crime, Hsiang et al. (2013) explicitly exclude studies that use a potentially biasing control variable. See also the chapter "bad control" in Angrist \& Pischke (2008).

${ }^{7}$ For instance, Dell et al. (2012) also obtain a statistically insignificant baseline effect.
} 
The hypothesis that only affected countries respond to temperature shocks receives confirmation in columns (4) to (6). In these estimations, I repeat the specifications of columns (1)-(3) but replace the historical temperature anomaly with the deviation-adjusted temperature measure (DeviationAdjustedTempAnomaly $y_{i, t}$ ). As described, this version emphasizes temperature shocks in countries with low seasonality and hence warm climate. It enters negative and with a stable and strongly statistically significant coefficient (1\% level) in all specifications. This result implies that rising temperature leads to a statistically significant decrease of sovereign creditworthiness for countries with low seasonality. Regarding the economic size, an increase of deviation-adjusted temperature anomalies by one standard deviation $\left(0.574^{\circ} \mathrm{C}\right)$ leads to a $0.135 \%$-point drop in EMBI returns. This magnitude corresponds to $3.47 \%$ of the standard deviation of EMBI returns in the estimation sample. While this effect is modest for now, the next section will investigate the susceptibility of countries towards temperature shocks in greater detail and identify more substantial effects.

- Table 6 around here -

\section{Channels and Discussion of Temperature-Sovereign Risk Connection}

The previous literature established that temperature shocks can be particularly harmful for warmer or poorer countries or affect certain economic sectors like agriculture or industrial production (Burke et al. 2015, Dell et al. 2012). I investigate such channels with respect to their impact on sovereign risk. Specifically, I analyze the general warmness of a country (5.1), its specialization towards different economic sectors (5.2), the effect of institutions (5.3) and ultimately a combination of all relevant channels (5.4) regarding their temperature-induced sovereign risk impact.

Methodically, I either analyze these channels in an interaction model as follows:

$\Delta$ SovereignCreditworthiness $_{i t}=\lambda_{1}$ TemperatureAnomaly $_{i t} *$ Channel $_{i t}+\lambda_{2}$ Channel $_{i t}$

$$
+\beta \text { TemperatureAnomaly } y_{i t}+\delta \text { Precip }_{i t}+\gamma_{i}+\gamma_{r t}+\epsilon_{i t}
$$


That is, the baseline estimation is repeated while TemperatureAnomaly is interacted with the channel of interest, for instance institutional quality. I expect channels that increase the detrimental impact of temperature shocks on sovereign creditworthiness to enter with a negative, while factors that cushion the effect of temperature on sovereign bond performance to carry a positive coefficient sign.

Some of the analyzed channels could be endogenous towards temperature, such as the share of agriculture on the economy. However, as shown by Nizalova \& Murtazashvili (2016) and Bun \& Harrison (2019), even if one of such channels could be endogenous in the single term, the interacted effect with temperature anomalies can still yield a consistent estimate. This inference holds as long as one of the variables in the interaction term is exogenously determined. This assumption holds plausibly for temperature shocks, as countries can hardly influence their own weather or reallocate because of it. Therefore, even if some channels could be endogenous with respect to temperature, I argue that the interaction terms allow for an unbiased interpretation.

I apply the interaction model for economic variables, as they have a plausibly linear effect on the temperature-sovereign risk relationship. However, some climate-related variables could have non-linear effects that are critical to certain thresholds. For instance, Burke et al. (2015) show that a country's temperature has a non-linear impact on GDP growth. As the interaction model above will only partially capture such non-linear effects, I follow the literature (e.g. Zhang et al. (2018), Graff Zivin \& Neidell (2014)) and estimate a bin-model for all climate-related channels:

$$
\begin{aligned}
\Delta \text { SovereignCreditworthiness }_{i t}= & \sum_{m} \lambda_{m} \text { TemperatureAnomaly } \text { A }_{i t} * \text { Channel }_{i}^{m} \\
& + \text { TemperatureAnomaly } i t+\delta \text { Precip }_{i t}+\gamma_{i}+\gamma_{r t}+\epsilon_{i t}
\end{aligned}
$$

In this way, a country is grouped into one of $m$ (time-invariant) bins. For instance, a country could be sorted into a bin for cold, mild or warm countries based on its average yearly temperature. In order to avoid multicollinearity, one bin has to be omitted in the regression. The estimated coefficient $\lambda_{m}$ yields the effect of a temperature anomaly increase of, for instance, the warm country group relative to the omitted reference group, for example the mild countries. Thereby, group-specific non-linear temperature effects are taken into account. 


\subsection{General Warmness}

Figure 3 depicts the histogram of every sample country's 1901-2018 temperature average. There is considerable heterogeneity visible in the warm- and coldness between the coldest (Russia, $-4.96^{\circ} \mathrm{C}$ ) and the hottest (Senegal, $28.03^{\circ} \mathrm{C}$ ) country. To investigate if these differences in climatic profiles affect the temperature-sovereign risk relationship, I construct five bins to group every country into: very cold, cold, mild, warm and very warm.

- Figure 3 around here -

I start by grouping according to percentiles: Countries equal to or below the 20th percentile of average annual temperature (from 1901-2018) are classified as "very cold". Countries in the 21 st to the 40th percentile of the sample-wide annual temperature distribution are classified as "cold" and so on. Using this data-driven procedure, I make sure that every bin has the same number of countries.

One drawback of this method is that the differences at the end of the distribution are less sharp. "Warm" countries have an average temperature of $24.36^{\circ} \mathrm{C}$ while "very warm" countries have only marginally hotter climate averaging $26.25^{\circ} \mathrm{C}$. Therefore, for a second procedure, I group according to $5^{\circ} \mathrm{C}$-intervals: "Very cold" includes countries with mean 1901-2018 temperatures below $10^{\circ} \mathrm{C}$, "cold" ranges between $10^{\circ} \mathrm{C}$ and $15^{\circ} \mathrm{C}$, "mild" between $15^{\circ} \mathrm{C}$ and $20^{\circ} \mathrm{C}$, "warm" between $20^{\circ} \mathrm{C}$ and $25^{\circ} \mathrm{C}$ and "very warm" above $25^{\circ} \mathrm{C}$. With this procedure, the number of countries in each bin varies. Table 5 shows the members of each bin and their mean temperature for both classifications.

- Table 5 around here -

I proceed by estimating both bin classifications according to equation (5). I omit the "cold" bin to avoid multicollinearity. ${ }^{8}$ Table 7 reports the results and Figures 4 and 5 depict the coefficients. I find that the interaction of the "very warm" category and temperature anomalies is both times negative and statistically significant at the $5 \%$ level. As in Burke et al. (2015), warmer countries seem to suffer more from temperature increases than milder tempered countries. For both models, the effect of "very warm" countries holds at least at the $10 \%$ level of statistical significance with respect to the cold but also the mild and very cold

\footnotetext{
${ }^{8}$ I only interact with the unadjusted historical temperature anomaly variable, as the deviation-adjusted temperature variable already captures countries with low seasonality and warm climate.
} 
category and for the $5^{\circ} \mathrm{C}$-interval model even towards the "warm" category (see Figures A.1 and A.2 in the online appendix).

Independent of the base category, summing the interaction coefficient of "very warm" countries and the single term coefficient of historical temperature anomalies gives the total size of the effect. For "very warm" countries, I find that a rise in historical temperature anomalies by $1^{\circ} \mathrm{C}$, i.e. the estimated global temperature increase since the pre-industrial age, leads to a decline in EMBI returns by $0.432 \%$-points in the percentile- and by $0.464 \%$-points in the $5^{\circ} \mathrm{C}$-interval model. These effects correspond to $11.1 \%$ or $11.9 \%$ of the EMBI returns' standard deviation in the sample. Although this projection is out-of-sample and subject to climate-related uncertainty, according to the model, a $2^{\circ} \mathrm{C}$ heating scenario would lead to falling sovereign creditworthiness of affected countries by roughly $25 \%$ of the recent EMBI standard deviation. One drawback of the EMBI growth data is that, as a financial market return variable, I cannot attach a dollar value to these effects. Still, the magnitude in terms of percentage points and standard deviation shares is quite substantial. The effect implies sharply rising sovereign borrowing costs for sovereigns that are susceptible to climate change.

- Table 7 and Figures 4 and 5 around here -

\subsection{Economic Sector Specialization}

In the following, I investigate if countries that are specialized in certain economic sectors are more susceptible to temperature deviating positively from its historical average. For instance, Auffhammer \& Schlenker (2014) summarize empirical studies on the tight relationship between agricultural production, weather outcomes and climate change. Furthermore, the literature linking temperature and labor productivity typically finds critical effects in manufacturing sectors (Cachon et al. 2012, Zhang et al. 2018). Lastly, countries specialized in fossil-fuel sectors could see their creditworthiness deteriorate because these industries might no longer have viable business models as climate change intensifies (ECB 2019).

To test the statistical effects of these channels, I interact the temperature anomaly variable with measures for sector specialization as described in equation (4). Though pure temperature anomalies are the primary interest of this specification, I also run the regressions using the deviation-adjusted anomaly measure to emphasize countries with lower seasonality and warmer weather. 
Table 8 shows the results for agricultural ((1)-(2)), manufacturing ((3)-(4)) and services ((5)-(6)) specialization, all measured by their share on GDP. Negative interaction effects would indicate that higher specialization in a sector leads to more detrimental temperature impacts on sovereign creditworthiness. However, while some coefficients of the interactions with temperature anomaly are negative in sign, none of them are statistically significant at conventional levels. Table A3 in the online appendix repeats these interactions with different scaling, for instance the employment instead of the GDP share, but the results stay statistically insignificant. Overall, the gathered evidence does not suggest that countries which are specialized in a certain economic sector are more (or less) susceptible to temperature increases with respect to their sovereign solvency.

Lastly, I interact with total share of oil, gas, coal, mineral and forest rents in relation to GDP (ResourceRentsToGDP) ((7)-(8)). However, there are once again no statistically significant interaction effects for either one of the temperature anomaly variables. Of course, it could still be the case that fossil industries captured in the resource-rent variable will come under stronger pressure in future years and thereby endanger the creditworthiness of their sovereign. Still, such effects seem to be either weak during my estimation period or not connected to the temperature shocks estimated in the model.

- Table 8 around here -

\subsection{Institutions}

The subsequent section investigates if the quality of a country's institutions differentiates the effect of temperature increases on sovereign risk. Better institutions make sure that countries have a stable political and business environment, low corruption and a government that can mobilize investments, provide common goods and respond to market failures or natural disasters. All these factors matter in the context of climate change, for instance if droughts or floods lead to physical damages that require swift government intervention, or if distributional consequences of temperature-induced costs need to be managed efficiently. Consistent with this argument, Kahn (2005) finds that the death toll from natural disasters is lower in countries with better institutions. In sum, better institutional quality could make a country more resilient to the various challenges global heating poses for emerging economies. 
In order to test the hypothesis of institutions driving the temperature-sovereign connection, I interact both temperature anomaly versions with a range of institutional measures. My main interest lies once again in the raw temperature anomaly measure as it proxies global heating directly and is more straightforward to interpret, but I will also post results for the deviation-adjusted version. The main interactions are with the World Bank's institutional measures for the quality of a country's rule of law (Table 9, columns (1)-(2)) and its control of corruption (columns (3)-(4)) which capture most of all business and legal aspects of institutions. I continue with interactions measuring the impact of political rights (columns (5)-(6)) and civil liberties (columns (7)-(8)) by Freedom House to see if free elections, freedom of speech and other politically- and societal-related aspects play a role.

Simply put, I find strong and robust evidence for all of these channels. Interactions with institutional variables for which higher values indicate better quality (rule of law, control of corruption) enter with positive, while measures which are indexed so that higher values imply lower quality (civil liberties, political rights) carry negative signs in all cases. For the pure temperature anomaly measure, all interactions are at statistical significance levels of $1 \%$ or $5 \%$. In the case of the deviation-adjusted measure, the coefficients are slightly weaker but statistically significant at conventional levels. In the online appendix, I interact further with the amount of income redistribution, the Polity2 index, and its components approximating democratic and authoritarian governments and find very close results (Table A4).

- Table 9 around here -

Concerning economic sizes, having a value in the rule of law index (which ranges between 0 and 100) at the 10th percentile (15.35) leads to a marginal temperature anomaly effect of $-0.148(=-0.209+0.00396 * 15.35)$ which is statistically significant at the $5 \%$ level. At this index level, a $1{ }^{\circ} \mathrm{C}$ increase in temperatures leads to a reduction in EMBI returns by $-0.148 \%$ points which is $3.8 \%$ of EMBI return standard deviation. While this effect is of a smaller magnitude compared to the "very warm" country coefficient, it still captures a non-negligible variation in EMBI returns. In contrast, having a rule of law index at the 90th percentile (69.23) leads to marginal temperature effect of 0.0654 that is statistically insignificant.

I expand the analysis to investigate if the results also hold for climate-related institutions. To this end, I draw data from the Notre Dame Global Adaption Initiative, which publishes the Notre Dame Global Adaption Index (ND-GAIN). This index takes both the climate- 
related adaptive readiness of a country as well as its physical and institutional vulnerability towards global heating into account. The index has a readiness component that covers the economic, governance and social-related institutions of a country that can provide resilience towards damages from climate change. The vulnerability component measures physical and topographical exposure risks and the dependency on climate-sensitive sectors. Theoretically, both the readiness and vulnerability component could affect sovereign risk in its interaction with rising temperatures.

Column (1) of Table 10 reports the results of the overall ND-GAIN interacted with temperature anomalies. I obtain a positive coefficient that is statistically significant closely before the $5 \%$ level, indicating that countries with stronger climate-related institutions suffer significantly less from rising temperature than less well-prepared countries. Results for the interaction between ND-GAIN and the deviation-adjusted temperature are similarly positive and significant just before the $5 \%$ level of statistical significance, suggesting again that countries with lower ND-GAIN scores suffer significant negative temperature shocks on their sovereign creditworthiness level.

Interactions with the readiness component (columns (3)-(4)) and the vulnerability component (columns (5)-(6)) of the ND-GAIN index reveal that the readiness part is driving the results. The corresponding interactions are positive and statistically significant at the $1 \%$ level, while the vulnerability interactions are statistically insignificant. This finding is in line with previous results, as the vulnerability component measures the dependency on climatevulnerable sectors, which were shown to be largely unrelated to the temperature-sovereign risk relationship in the previous section. On the other hand, the readiness component captures climate-related governance factors that correlate positively with the previous measures of institutional quality. The high statistical significance could suggest that climate-related institutional features, like disaster protection or frameworks to support investments in adaptive capacities are crucial to deal with rising temperatures.

In sum, this section provides robust evidence that institutions strongly influence the relationship between rising temperature and sovereign creditworthiness. Countries with lower institutional quality, both in a traditional and in a climate-related context, have so far been hit significantly harder by temperature deviating from its historical levels. This result suggests that better institutions can make a country more resilient towards the physical damages of 
climate change, which is also argued by the IPCC (2018). As future global heating will lead to growing damages, transition costs and distributional issues, having stronger institutions to manage these challenges could be a viable strategy in climate change adaption processes.

- Table 10 around here -

\subsection{Combining relevant Channels}

A channel that could be related to the impact of institutional quality is economic development. Therefore, I interact temperature anomalies with a country's GDP per capita. Column (1) in Table 11 confirms that the level of economic development matters, in that poorer countries' sovereign creditworthiness is statistically significantly stronger damaged by a temperature shock than those of economically more developed countries.

However, it could be the case that poorer countries have larger susceptibility to rising temperatures because they tend to have worse institutions. It could also be the other way around, and the effect of worse institutions only works through the associated lower level of economic development. More broadly, the vulnerability of the warmest countries uncovered in Section 5.1 could also be interrelated with institutions and development. For instance, Easterly \& Levine (2003) show that countries in tropical climate zones tend to develop worse institutions which lowers their economic progress (see also Sachs (2001)). Indeed, annual average temperatures and the rule of law index correlate negatively in the sample (-0.165), indicating that warmer countries tend to have worse institutions.

A possible if not perfect way to test which channels ultimately matter for the temperaturesovereign relationship is to combine all relevant interactions in a single model. I start by adding the interaction of temperature anomalies and the rule of law index, as one of the institutional variables (results also hold for other measures), to the model with interacted GDP per capita (column (2)). While the interaction coefficient for rule of law remains statistically significant and of similar size than in Table 9, the GDP per capita interaction with temperature decreases in size and becomes statistically insignificant. This finding provides some confirmation that the effect of lower economic development on the temperature-sovereign relationship is mostly driven by the fact that poorer countries tend to have worse institutions.

In column (3), I add the deviation-adjusted temperature variable to the specification of column (2). The variable remains negative and statistically significant in column (3), but the 
interacted rule of law coefficient also stays stable and significant. GDP per capita remains statistically insignificant. This result suggests that, even after controlling for temperature shocks in warmer countries, institutional quality can still cushion the impact of a temperature shock to a significant degree. This finding is confirmed in column (4) in which I replace the deviation-adjusted temperature measure with the five bins representing very cold, cold, mild, warm and very warm countries according to $5^{\circ} \mathrm{C}$-intervals. Leaving out the cold country bin, I find that both the interaction of temperature with the very warm country bin and with the rule of law index continue to stay statistically significant and similar in size than before.

While the long-run effects of climate on institutional development are difficult to entangle and beyond the scope of this paper, the fact that the impact of institutions on the temperature-sovereign relationship continues to hold even after controlling for the warmness of a country shows that the institution-channel does not work purely through the climatechannel. In that sense, policy makers, independent of the warmness of their country, have an incentive to improve institutional quality, as it can cushion the impact of rising temperatures on their sovereign risk level.

- Table 11 around here -

\section{Robustness Tests}

\subsection{Changing the Fixed Effects Specification}

In order to conduct robustness checks, I repeat those specifications that yielded the most decisive results in the previous sections. These include the deviation-adjusted temperature variable (Table 6, column (6)), the bin-regression analyzing the warmness of countries using $5{ }^{\circ} \mathrm{C}$-intervals (Table 7, column (2)) and the interaction with institutional characteristics from which I choose the rule of law index (Table 9, column (1), results also hold for other institutional variables). For the bin-regression, I omit the "cold" country category because it provides a distinctive comparison group to the "very warm" country group. However, results also hold for omitting other groups for the majority of robustness checks. More importantly, I am interested in the total effect of the "very warm" country group interaction, which is independent of the omitted bin. 
I start by changing the fixed effects setting for each of these three specifications. First, I deconstruct the interaction of region and year-month fixed effects and instead only include year-month time effects, thus omitting the regional component (Table 12, columns (1)-(3)). Second, I re-include the region times month-year effects and in addition interact the country fixed effects with a year time fixed effect (columns (4)-(6)). Though I am not aware of a paper in the relevant literature using such a country-year effect, the interaction controls for time-fixed differences between countries within each year. Lastly, I control for region times month-year and additional country times quarter fixed effects (columns (7)-(9)). The latter interaction absorbs seasonal differences that vary over each quarter.

In sum, the main results of the paper stay intact for each of these modifications. Dropping the region fixed effects only marginally changes the coefficients. The country by year fixed effects, in contrast, reduce the statistical significance of the deviation-adjusted temperature anomaly to the $10 \%$ level, and also lower the total effect of very warm countries from -0.464 in the baseline to -0.320 in column (5). Still, this specification is unusual in the literature and the overall direction of the results is the same as before. Interacting the country with quarter fixed effects yields stable and even slightly stronger results than in the baseline.

- Table 12 around here -

\subsection{Changing the dependent Variable}

Next, I test if the main results hold when using a different dependent variable. All specifications so far used monthly returns of the EMBI index. A natural alternative for this measure are differences in the EMBI spread instead of the index level.

Table 13 repeats the three main regressions using monthly first differences of EMBI spreads as the dependent variable (columns (1)-(3)). All results continue to stay statistically significant if on somewhat lower levels. The coefficient signs are now reversed as rising EMBI spread changes indicate lower sovereign creditworthiness. Regarding the economic magnitude, an increase of $1^{\circ} \mathrm{C}$ of the anomaly measure in "very warm" countries leads to a 9.62-point increase in EMBI spread changes. This effect is $11.98 \%$ of the overall EMBI spread change standard deviation (80.34) and thus extremely close to the $11.9 \%$ obtained for the EMBI index returns. 
In order to investigate the validity of the results for a different variable than the EMBIs, I collect sovereign CDS data. However, this data is only available since roughly 2008 and only for 37 of the 54 panel countries. With these limitations in mind, I construct changes in the CDS spread the same way as with the EMBI spread, i.e. I take first differences, set zero returns to missing and winsorize at the 1st and 99th percentile. I use CDS spread changes as a new dependent variable in columns (4)-(5). I do not report the regression using the temperature bin interactions because the grouping process is significantly biased due to the lower number of countries (though the results point in a similar direction as before). The interaction with the rule of law index is negative and statistically significant at the $5 \%$ level, which corroborates the previous results. The deviation-adjusted measure enters positively but is not statistically significant. However, the imprecise estimation could likely be due to the lower number of observations, since the coefficient size is still large. An increase of deviation-adjusted temperature by one standard deviation of the estimation sample (0.627) increases CDS changes by 5.19 points which is $7.3 \%$ of the CDS standard deviation (71.05).

- Table 13 around here -

\subsection{Dropping Countries with lower Data Coverage, larger Landmass or political Instability}

In the main specification, I included all countries with liquid EMBI return data of at least six years. I chose this criterion to manage the trade-off between having a large panel and sufficient observations for each country in the sample. In columns (1)-(3) of Table 14, I set the inclusion criterion to ten years (120 months) of liquid EMBI return data. 15 countries in the original sample are affected by this requirement (Angola, Azerbaijan, Belarus, Bolivia, Costa Rica, Guatemala, India, Jordan, Latvia, Lithuania, Mongolia, Namibia, Romania, Senegal, Zambia). I drop these countries and repeat the three main regressions. The number of observations only decreases slightly as a result of this adjustment, and all the main effects retain their statistical significance. The effect of temperature increases in the warmest countries even rises somewhat, in both magnitude and significance.

One further concern I address deals with countries covering a huge landmass. Nations like Russia or China could have several climate zones which makes their temperature average only a rough measure for weather fluctuations. Therefore, I drop the ten countries with 
the largest landmass from my sample (Russia, China, Brazil, India, Argentina, Kazakhstan, Mexico, Indonesia, Mongolia, Peru) and repeat the main regressions. Columns (4)-(6) reveal that the number of observations now decreases more notably. However, the main results remain broadly intact. Deviation-adjusted temperature shocks even increase, as does the interacted effect of institutions and temperature anomalies. The "very warm" country bin is now marginally insignificant just before the $10 \%$ level, perhaps because of the lower number of observations or the changing number of countries in each bin. Nevertheless, the total effect of this group still has the same size as in the main regression (-0.443).

The last issue in the sample selection that I address concerns politically unstable countries. Nations that experienced severe domestic instability or war might yield unreliable data (though political instability can itself be a result of temperature shocks, as Hsiang et al. (2013) show). Therefore, in columns (7)-(9), I drop all countries with a World Bank PoliticalStability-Score (ranging from 0 to 100) below the sample median (38.37). This criterion permanently excludes Angola, Azerbaijan, Colombia, Georgia, Guatemala, India, Indonesia, Iraq, Lebanon, Nigeria, Pakistan, Peru, Philippines, Russia, Turkey and Venezuela from the sample, and affects several other countries temporarily. With roughly half the sample size, the coefficient of deviation-adjusted temperature shocks remains similar in size than before and statistically significant at the $10 \%$ level. Similar to the landmass test, the "very warm" country bin is marginally insignificant just before the $10 \%$ level, but the total effect size is remains close to the main baseline. The rule of law interaction is positive and statistically significant at the $5 \%$ level.

- Table 14 around here -

\subsection{Further Tests in the Online Appendix}

In the online appendix of the paper, I use a bin model to test if countries with lower seasonality face a larger temperature-sovereign risk effect, for which I find strong confirmation. Furthermore, I test if there are month- or season-specific effects of temperature shocks, for instance during the summer period. However, there seems to be no indication of such monthspecific effects driving the temperature-sovereign connection.

I show that the results for economic sector specialization (Section 5.2) and institutional quality (Section 5.3) also hold for other measures. For economic sectors, the results stay 
insignificant with different scaling measures. For institutional metrics, there are significant effects for larger tax redistribution, more democratic and/or less authoritarian governments.

Results are also stable when introducing a lag structure for temperature shocks, or for changing the historical average period for temperature deviations from 1950 to 1930, 1940, 1960 or 1970. I also introduce a further temperature measure that captures temperature volatility instead of absolute deviations. This measure is, on its own, statistically significant in affecting sovereign risk.

Furthermore, tests with interactions of variables for debt sustainability (such as debt-toGDP) are shown not to be significant for the temperature-sovereign relationship.

Lastly, I show that the results hold for double-clustering the standard errors, and that the main temperature variables are stationary.

\section{Testing for Underlying Mechanisms}

\subsection{Impact of natural Disasters on GDP Growth and political Stability}

Though this paper firmly establishes evidence that higher temperatures hurt sovereign creditworthiness of warmer countries, less is clear about the underlying mechanisms of this channel. This lack of knowledge is also true for related work, and it beyond the scope of this paper to carve out the precise mechanisms of the temperature-sovereign risk relationship. Nevertheless, this section looks at a possible channel of how temperature affects the economies of the warmest countries, namely in their impact through natural disasters.

Table 4 already indicated that heat-related natural disasters, such as droughts or wildfires, correlate with higher temperature deviations. Therefore, I test if such disasters also hurt the economic performance in warmer countries, which could likely spill over to their sovereign risk. To do so, I collapse the dataset to the yearly level and estimate the following model:

$$
\begin{aligned}
\text { EconomicPerformance }_{i t}= & \lambda_{1} \text { Disaster }_{i t} * \text { VeryWarmCountry } \\
& +\lambda_{2} \text { Disaster }_{i t} \\
& +\lambda_{3} \text { VeryWarmCountry }_{i}+\text { SPrecip }_{i t}+\gamma_{i}+\gamma_{r t}+\epsilon_{i t}
\end{aligned}
$$

First, I regress quarterly GDP growth as a measure for economic performance, which is winsorized and aggregated to the annual level, on an indicator for occurring natural disasters. This indicator is a dummy on the monthly level. Hence, on a yearly level, the indicator ranges 
between 0 and 1, depending on the number of months a disaster took place in a given year. I include country as well as region-year fixed effects, and control for precipitation, similar to the baseline model. Finally, I interact disasters with a dummy for the "very warm" country group according to the $5^{\circ} \mathrm{C}$-intervals. Thus, the model tests if the impact of natural disasters on economic performance is differentiated if they occur in the warmest countries. I do not estimate another bin model, as the number of disasters can vary between each bin, making such a set-up imprecise.

Table 16 reports the results for the disaster types droughts, droughts with a damage report (and thus likely more severe), wildfires, floods, storms and earthquakes. I find that the coefficient for wildfires (column (3)) and for droughts with a damage report (column $(2))$, interacted with warmest country dummy, is negative and statistically significant at the $1 \%$ level. For all droughts, the effect is at the $10 \%$ level of statistical significance (column (1)). Hence, for these heat-related disasters, there is evidence that they hurt the economic performance in particular in the warmest countries. ${ }^{9}$

Results in Table 17 allow a similar conclusion. Here, I use the Political Stability Score of the World Bank as a measure for economic performance. During droughts with reported damage (column (3)), the warmest countries experience significantly stronger (1\% level) declines in political stability than the other panel countries. The interaction coefficient of wildfires is negative and large in size, but statistically insignificant, perhaps because wildfires (unlike droughts) are typically short-lived events. Though these results require further research, they provide some evidence that warmer countries suffer more from heat-related natural disasters, which might likely spill over to their sovereign risk, which provides a possible explanation for the temperature-sovereign risk relationship.

\subsection{Testing for Transition Risks}

Though it is, as described in Section 2, extremely difficult to differentiate between physical and transition risks in the temperature literature, I conduct a test that could possibly detect transition risks. To this end, I use the Paris Climate Agreement, which was sealed in December 2015, as a transition shock. With the Paris Agreement, almost all countries in the world agreed to limit global heating to well below $2^{\circ} \mathrm{C}$. If temperature increases also feature

\footnotetext{
${ }^{9}$ Note that of the 716 drought months in the sample, $19.41 \%$ occurred in the warmest countries $(18.02 \%$ for droughts with damage, $20.05 \%$ for wildfires), hence, such disasters can occur in all country groups.
} 
a transition risk component, it could be the case that temperature shocks have stronger impacts on sovereign creditworthiness since the Paris Agreement, because investors are more sensitive towards climate issues.

To test this channel, I interact the three main regressions as well as raw temperature anomalies with a time dummy for the Paris Agreement that is 1 after December 2015. For the temperature anomaly and the deviation-adjusted temperature measure, the Paris dummy does not differentiate the impact of these variables, as the interaction effects are statistically insignificant (Table 15, columns (1)-(2)). The results are similar for "very warm" countries and institutions (columns (3)-(4)): The double interaction of temperature and rule of law remains statistically significant and comparable to previous results, whereas the triple interaction with the Paris dummy is small and statistically insignificant. Although this is no definitive result, it could suggest that temperature shocks are first and foremost a physical risk source, which is largely independent of climate agreements or transition risks.

- Table 15 around here -

\section{Conclusion}

I extend the literature on temperature fluctuations to finance, specifically the sovereign debt performance of emerging economies. To this end, I collect monthly temperature data since 1901 for 54 emerging markets. For each country, I calculate the temperature deviation of every month from this month's 1901-1950 temperature average. I run my main empirical analysis from $1994 \mathrm{~m} 1$ to $2018 \mathrm{~m} 12$, up until this temperature anomaly is on average $0.84^{\circ} \mathrm{C}$, reflecting past climate change trends. In line with previous literature, I argue that rising temperature deviations approximate physical weather and climate damages.

I regress Emerging-Market-Bond-Index returns on temperature anomalies while controlling for established country, time and region fixed-effects. My main result is that the effects of temperature anomalies on the cost of sovereign debt critically hinge on conditioning factors. Temperature deviations lower sovereign bond performance (i.e. increase sovereign risk) significantly for countries that are (i) warmer on average, and (ii) have lower institutional quality, both in terms of traditional- and climate-related metrics. Importantly, the effects of institutional quality and the warmness of a country on the temperature-sovereign risk 
relationship hold simultaneously, which implies that stronger institutions can improve the resilience of a country towards climate change, independent of its climatic profile.

The economic effects of temperature increases are more than noteworthy. According to my analysis if a country with an average annual temperature above $25^{\circ} \mathrm{C}$ faces a $1{ }^{\circ} \mathrm{C}$ increase in monthly temperature compared to its historical mean, its EMBI returns are lowered by 0.464 percentage points on average. This effect corresponds to $11.9 \%$ of the EMBI returns' overall standard deviation. Hence, a $2^{\circ} \mathrm{C}$ global heating scenario could lower EMBI returns of affected countries by roughly a quarter of their overall standard deviation.

This magnitude suggests that, in the absence of climate-adaption strategies, affected countries likely face considerable increases in their sovereign borrowing costs if temperatures continue to rise due to climate change. These results also raise distributional questions: As of 2017, the countries in my panel were responsible for just $36.6 \%$ of accumulated historical global $\mathrm{CO}_{2}$ emissions but posed $66.2 \%$ of the global population. Policy action to limit the degree of global heating and to build adaptive capacities through stronger institutional frameworks are therefore called for. 


\section{References}

Acemoglu, D., Johnson, S. \& Robinson, J. A. (2002), 'Reversal of fortune: Geography and institutions in the making of the modern world income distribution', The Quarterly Journal of Economics 117(4), 1231-1294.

Addoum, J. M., Ng, D. T. \& Ortiz-Bobea, A. (2020), 'Temperature shocks and establishment sales', The Review of Financial Studies 33(3), 1331-1366.

Adhvaryuy, A., Kalaz, N. \& Nyshadham, N. (2019), 'The light and the heat: Productivity co-benefits of energy-saving technology', Review of Economics and Statistics pp. 1-36.

Angrist, J. D. \& Pischke, J.-S. (2008), Mostly harmless econometrics: An empiricist's companion, Princeton university press.

Auffhammer, M. \& Schlenker, W. (2014), 'Empirical studies on agricultural impacts and adaptation', Energy Economics 46, 555-561.

Augustin, P. \& Tédongap, R. (2016), 'Real economic shocks and sovereign credit risk', Journal of Financial and Quantitative Analysis pp. 541-587.

Bank of England (2018), 'Transition in thinking: The impact of climate change on the UK banking sector'.

Bansal, R., Kiku, D. \& Ochoa, M. (2016), 'Price of long-run temperature shifts in capital markets'. NBER Working Paper No. 22529.

Barrios, S., Bertinelli, L. \& Strobl, E. (2010), 'Trends in rainfall and economic growth in Africa: A neglected cause of the African growth tragedy', The Review of Economics and Statistics 92(2), 350-366.

Beirne, J., Renzhi, N. \& Volz, U. (2021a), 'Bracing for the typhoon: Climate change and sovereign risk in southeast asia', Sustainable Development .

Beirne, J., Renzhi, N. \& Volz, U. (2021b), 'Feeling the heat: Climate risks and the cost of sovereign borrowing, International Review of Economics 83 Finance.

Bolton, P., Despres, M., Pereira da Silva, L. A., Samama, F. \& Svartzman, R. (2020), 'The green swan - Central banking and financial stability in the age of climate change'. Bank for International Settlements.

Bolton, P. \& Kacperczyk, M. (2020), 'Do investors care about carbon risk?'. NBER Working Paper No. 26968.

Boston Common Asset Management (2018), 'Banking on a low-carbon future: Are the world's largest banks stepping up to the risks \& opportunities of climate change?'. http://news.bostoncommonasset.com/wp-content/uploads/2018/02/ Banking-on-a-Low-Carbon-Future-2018-02.pdf.

Bun, M. J. \& Harrison, T. D. (2019), 'OLS and IV estimation of regression models including endogenous interaction terms', Econometric Reviews 38(7), 814-827. 
Burke, M. B., Miguel, E., Satyanath, S., Dykema, J. A. \& Lobell, D. B. (2009), 'Warming increases the risk of civil war in Africa', Proceedings of the national Academy of sciences 106(49), 20670-20674.

Burke, M., Hsiang, S. M. \& Miguel, E. (2015), 'Global non-linear effect of temperature on economic production', Nature 527(7577), 235-239.

Cachon, G. P., Gallino, S. \& Olivares, M. (2012), 'Severe weather and automobile assembly productivity'. Columbia Business School Research Paper No 12/37.

Cevik, S. \& Jalles, J. T. (2020), 'This changes everything: climate shocks and sovereign bonds'.

Delis, M., De Greiff, K. \& Ongena, S. (2018), 'Being stranded on the carbon bubble? Climate policy risk and the pricing of bank loans'. SFI Research Paper 8-10, University of Zurich.

Dell, M., Jones, B. F. \& Olken, B. A. (2012), 'Temperature shocks and economic growth: Evidence from the last half century', American Economic Journal: Macroeconomics 4(3), 6695.

Dell, M., Jones, B. F. \& Olken, B. A. (2014), 'What do we learn from the weather? The new climate-economy literature', Journal of Economic Literature 52(3), 740-98.

Deryugina, T. \& Hsiang, S. M. (2014), 'Does the environment still matter? Daily temperature and income in the United States'. NBER Working Paper No. 20750.

Easterly, W. \& Levine, R. (2003), 'Tropics, germs, and crops: How endowments influence economic development', Journal of monetary economics 50(1), 3-39.

ECB (2019), 'Financial stability review May 2019'.

Eichler, S. (2014), 'The political determinants of sovereign bond yield spreads', Journal of International Money and Finance 46, 82-103.

ESRB (2016), 'Too late, too sudden: Transition to a low-carbon economy and systemic risk'. Reports of the Advisory Scientific Committee No 6.

Felbermayr, G. \& Gröschl, J. (2014), 'Naturally negative: The growth effects of natural disasters', Journal of development economics 111, 92-106.

Financial Stability Institute (2019), 'Turning up the heat - Climate risk assessment in the insurance sector'. FSI Insights on policy implementation No 20.

Germanwatch (2019), 'Global climate risk index 2020'. https://germanwatch.org/sites/ germanwatch.org/files/20-2-01e\%20Global\%20Climate\%20Risk\%20Index $\% 202020$ _ 13.pdf.

Graff Zivin, J. \& Neidell, M. (2014), 'Temperature and the allocation of time: Implications for climate change', Journal of Labor Economics 32(1), 1-26.

Harris, I., Osborn, T. J., Jones, P. \& Lister, D. (2020), 'Version 4 of the cru ts monthly high-resolution gridded multivariate climate dataset', Scientific data 7(1), 1-18. 
Heal, G. \& Park, J. (2014), 'Feeling the heat: Temperature, physiology \& the wealth of nations'. NBER Working Paper No. 19725.

Hilscher, J. \& Nosbusch, Y. (2010), 'Determinants of sovereign risk: Macroeconomic fundamentals and the pricing of sovereign debt', Review of Finance 14(2), 235-262.

Hsiang, S. M., Burke, M. \& Miguel, E. (2013), 'Quantifying the influence of climate on human conflict', Science 341(6151), 1235367.

Huynh, T. \& Xia, Y. (2020), 'Climate change news risk and corporate bond returns', Journal of Financial and Quantitative Analysis, forthcoming .

IPCC (2018), 'Global warming of $1.5^{\circ} \mathrm{C}$. An IPCC Special Report on the impacts of global warming of $1.5^{\circ} \mathrm{C}$ above pre-industrial levels and related global greenhouse gas emission pathways, in the context of strengthening the global response to the threat of climate change, sustainable development, and efforts to eradicate poverty (summary for policymakers)', Intergovernmental Panel on Climate Change .

Kahn, M. E. (2005), 'The death toll from natural disasters: the role of income, geography, and institutions', Review of economics and statistics 87(2), 271-284.

Kling, G., Lo, Y. C., Murinde, V. \& Volz, U. (2018), 'Climate vulnerability and the cost of debt'. Available at SSRN 3198093.

Kling, G., Volz, U., Murinde, V. \& Ayas, S. (2021), 'The impact of climate vulnerability on firmsâ ${ }^{\mathrm{TM}}$ cost of capital and access to finance', World Development 137, 105131.

Klusak, P., Agarwala, M., Burke, M., Kraemer, M. \& Mohaddes, K. (2021), 'Rising temperatures, falling ratings: The effect of climate change on sovereign creditworthiness'. CAMA Working Paper.

Koetter, M., Noth, F. \& Rehbein, O. (2019), 'Borrowers under water! Rare disasters, regional banks, and recovery lending', Journal of Financial Intermediation p. 100811.

Moody's (2016), 'Environmental risks - sovereigns: How Moody's assesses the physical effects of climate change on sovereign issuers'. https://www.moodys.com/research/ Moodys-sets-out-approach-to-assessing-the-credit-impact-of--PR_357629.

Nizalova, O. Y. \& Murtazashvili, I. (2016), 'Exogenous treatment and endogenous factors: Vanishing of omitted variable bias on the interaction term', Journal of Econometric Methods 5(1), 71-77.

Painter, M. (2020), 'An inconvenient cost: The effects of climate change on municipal bonds', Journal of Financial Economics 135(2), 468-482.

Pankratz, N., Bauer, R. \& Derwall, J. (2019), 'Climate change, firm performance, and investor surprises', Available at SSRN 3443146 .

Pankratz, N. \& Schiller, C. (2019), 'Climate change and adaptation in global supply-chain networks', Available at SSRN 3475416 .

Ripple, W. J., Wolf, C., Newsome, T. M., Barnard, P. \& Moomaw, W. R. (2019), 'World scientists' warning of a climate emergency', BioScience . 
Sachs, J. D. (2001), 'Tropical underdevelopment'. NBER Working Paper No. 8119.

Somanathan, E., Somanathan, R., Sudarshan, A., Tewari, M. et al. (2018), 'The impact of temperature on productivity and labor supply: Evidence from Indian manufacturing'. Becker Friedman Institute Working Paper No. 2018-69.

Volz, U., Beirne, J., Ambrosio Preudhomme, N., Fenton, A., Mazzacurati, E., Renzhi, N. \& Stampe, J. (2020), 'Climate change and sovereign risk'.

Zhang, P., Deschenes, O., Meng, K. \& Zhang, J. (2018), 'Temperature effects on productivity and factor reallocation: Evidence from a half million Chinese manufacturing plants', Journal of Environmental Economics and Management 88, 1-17. 


\section{Tables and Figures}

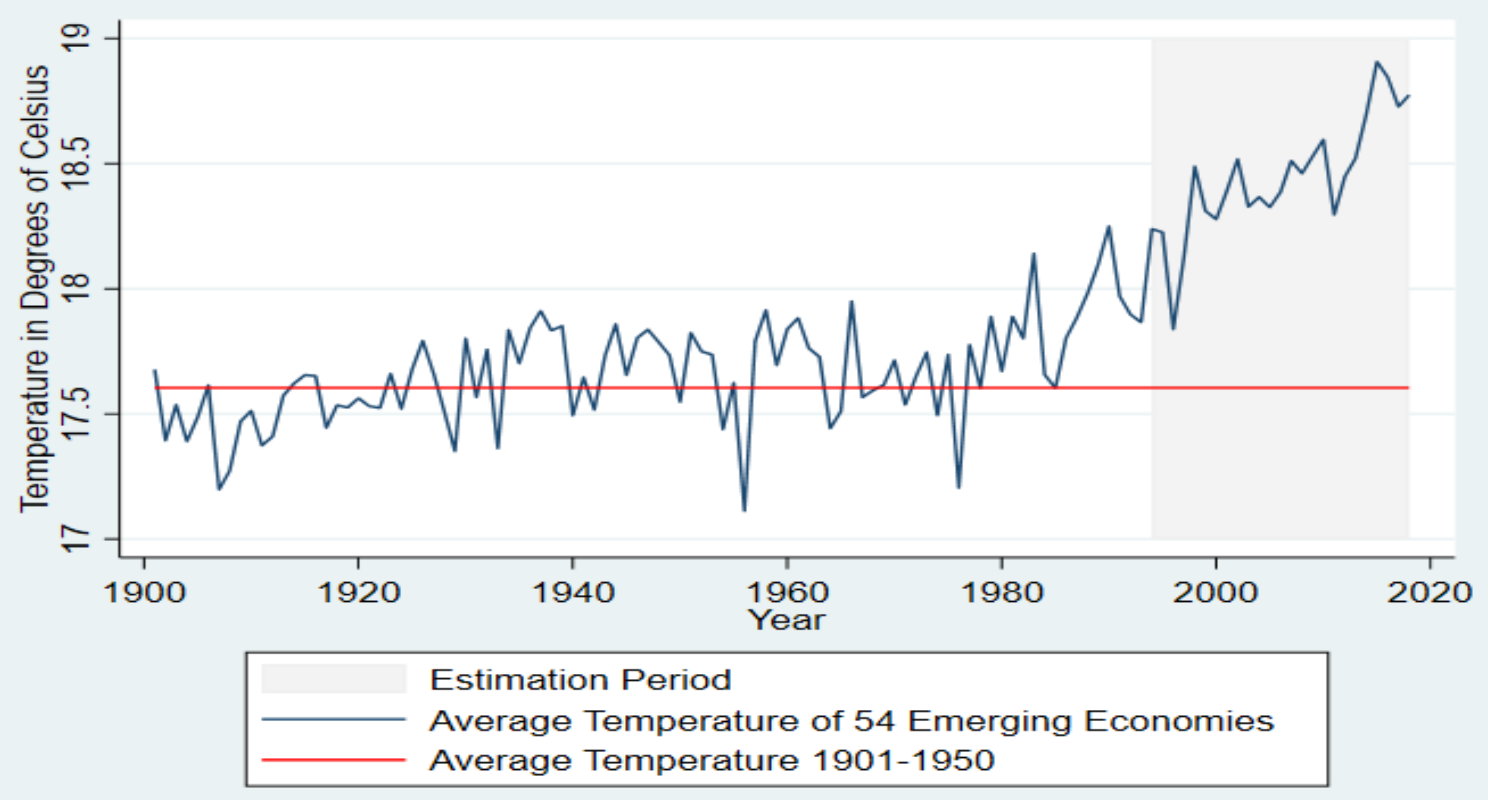

Figure 1: Average annual temperature of 54 emerging economies in the sample from 1901-2018 and 1901-1950 temperature average.

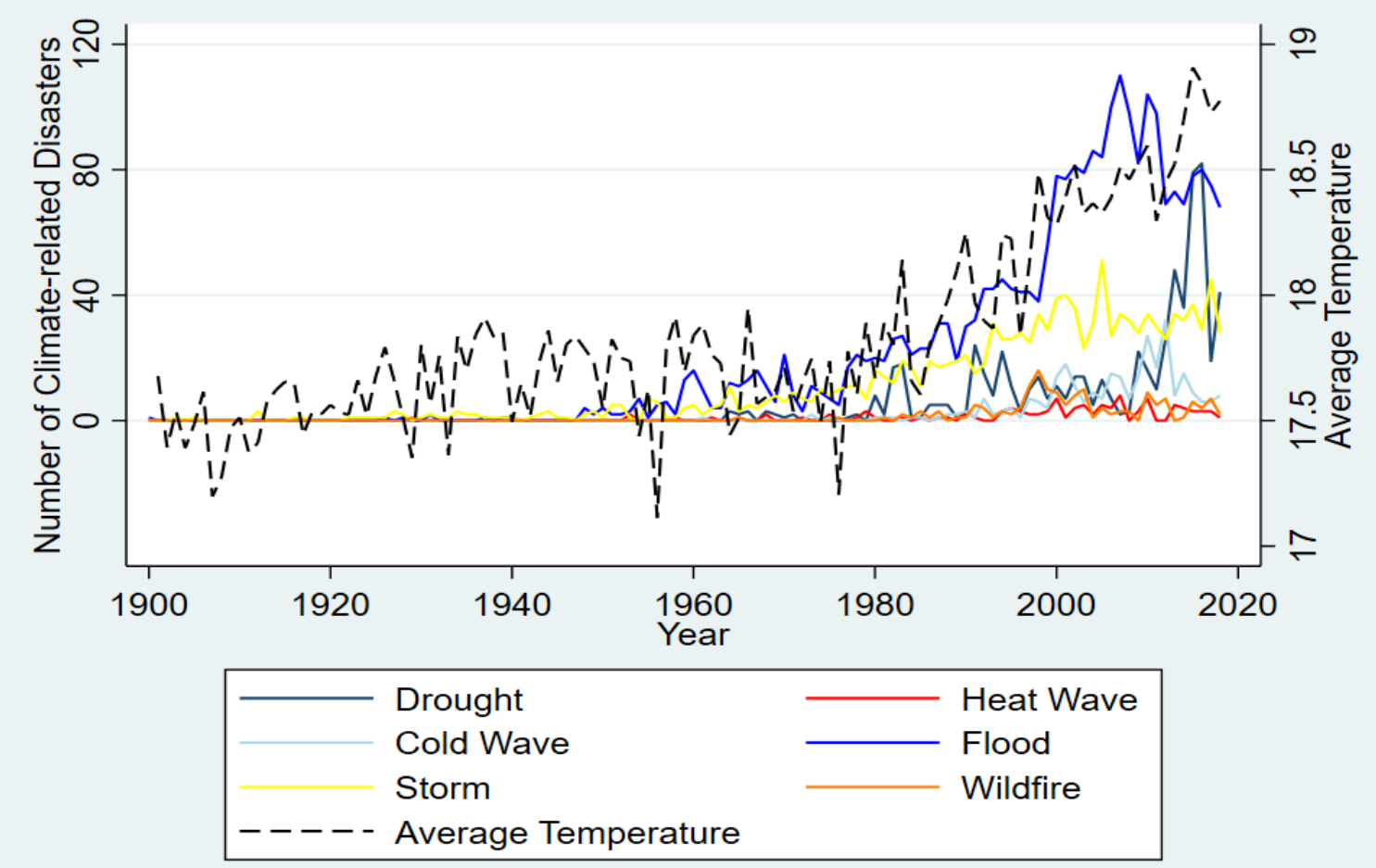

Figure 2: Number of climate-related natural disasters and average temperature of panel countries. 


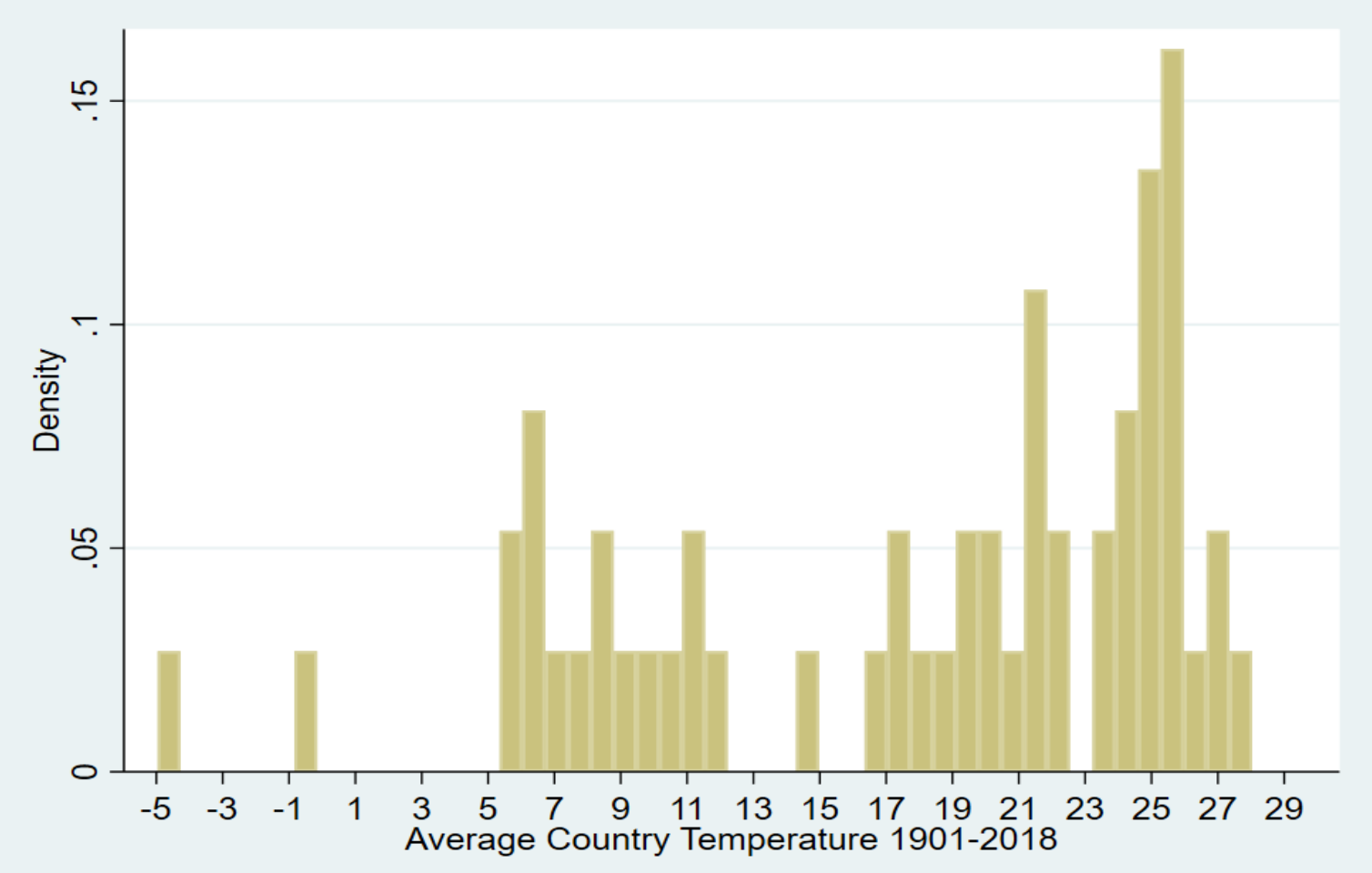

Figure 3: Histogram of average temperature of every sample country.

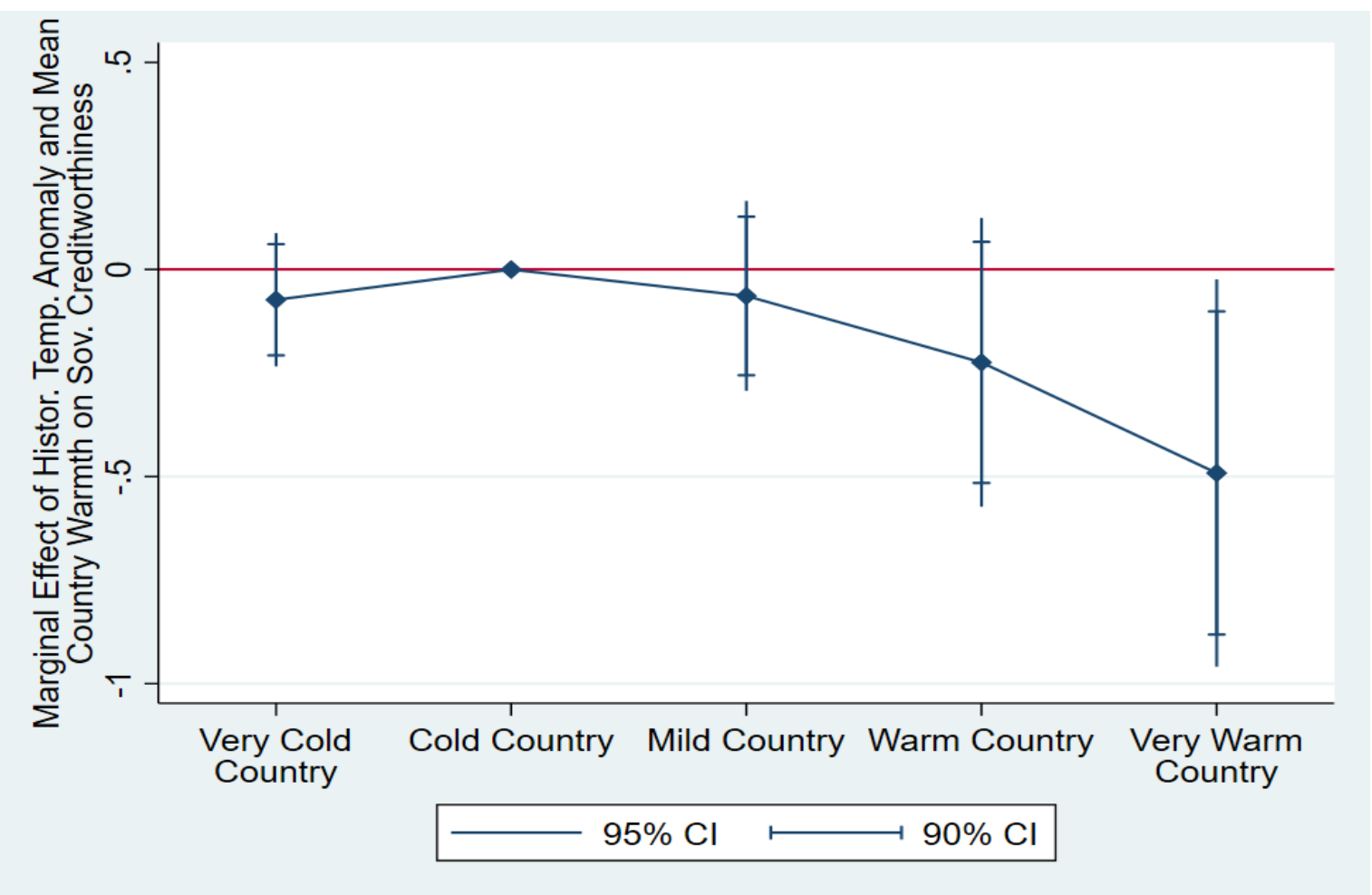

Figure 4: Coefficients estimated in Table 7 for climatic bins according to percentiles of average temperature. 


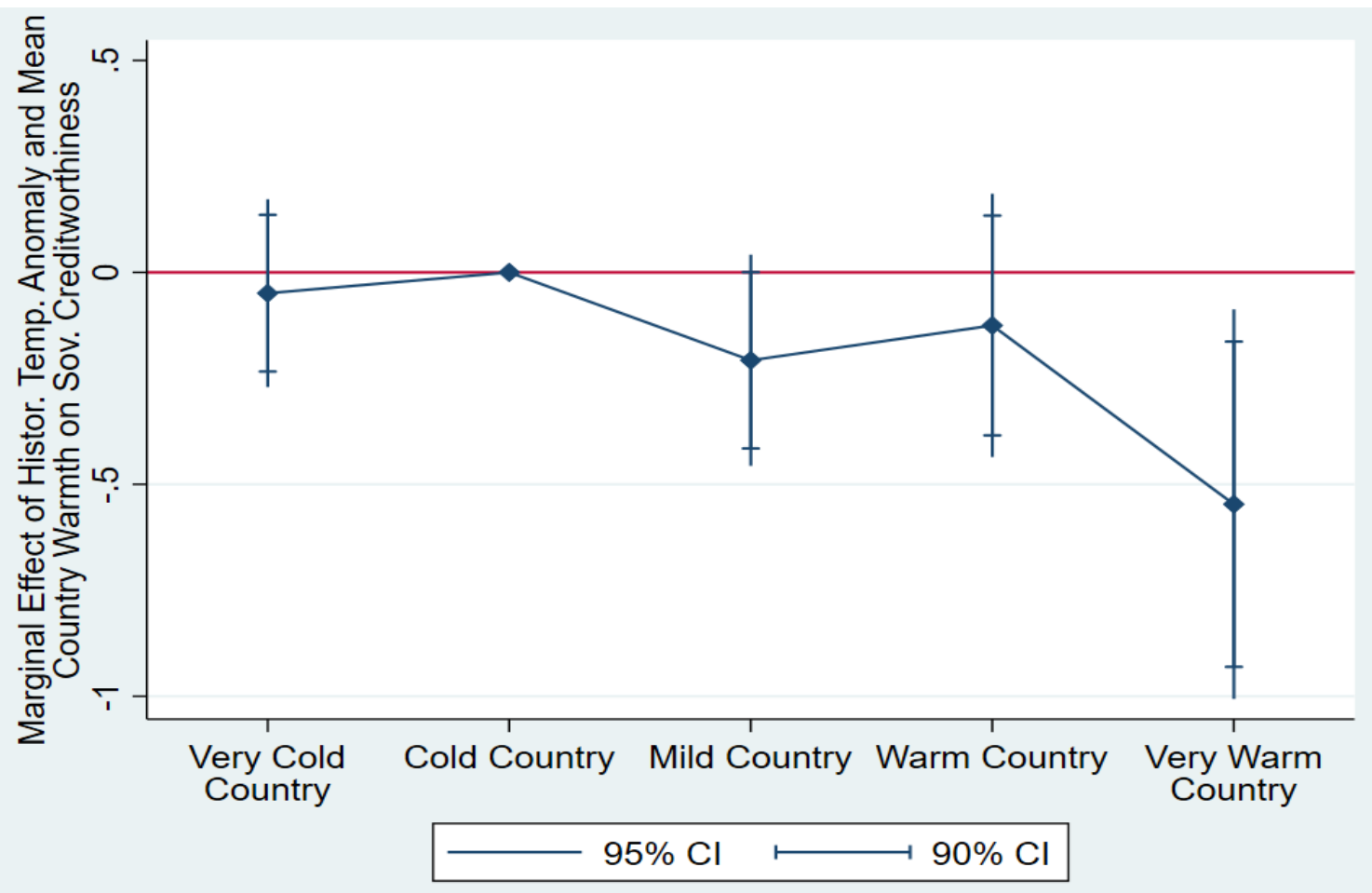

Figure 5: Coefficients estimated in Table 7 for climatic bins according to $5^{\circ} \mathrm{C}$-intervals of average temperature.

Table 1: Distinction between physical and transition climate change risks.

\begin{tabular}{llll}
\hline Risk Type & \multicolumn{1}{c}{$\begin{array}{c}\text { Implications for } \\
\text { Credit }\end{array}$} & \multicolumn{1}{c}{$\begin{array}{c}\text { Implications for } \\
\text { Markets }\end{array}$} & \multicolumn{1}{c}{$\begin{array}{c}\text { Implications for } \\
\text { Business }\end{array}$} \\
\hline \multirow{3}{*}{ Physical } & $\begin{array}{l}\text { Increasing flood risk } \\
\text { to mortgage portfolios; } \\
\text { declining agricultural output; } \\
\text { increasing default rates }\end{array}$ & $\begin{array}{l}\text { Severe weather events can lead } \\
\text { to re-pricing of sovereign debt }\end{array}$ & $\begin{array}{l}\text { Severe weather events can } \\
\text { impact business continuity }\end{array}$ \\
& $\begin{array}{l}\text { Tightening efficiency } \\
\text { standards impact } \\
\text { property exposures; } \\
\text { stranded assets impair } \\
\text { loan portfolios; } \\
\text { disruptive technology leads } \\
\text { to auto finance losses }\end{array}$ & $\begin{array}{l}\text { Tightening climate-related policy } \\
\text { leads to re-pricing of securities } \\
\text { and derivatives }\end{array}$ & $\begin{array}{l}\text { Changing sentiment on } \\
\text { climate issues leads to } \\
\text { reputational risks }\end{array}$ \\
\hline
\end{tabular}

Source: Bank of England (2018). 
Table 2: List of included countries and region classification

\begin{tabular}{ll}
\hline Region & Countries \\
\hline \multirow{2}{*}{ Asia-Pacific } & China, India, Indonesia, Malaysia, Mongolia, Pakistan, \\
& Philippines, Vietnam \\
Eastern Europe \& Central Asia & Azerbaijan, Belarus, Croatia, Georgia, Hungary, Kazakhstan, \\
& Latvia, Lithuania, Poland, Romania, Russia, Serbia, Ukraine \\
& Argentina, Belize, Bolivia, Brazil, Chile, Colombia, Costa Rica, \\
Latin America \& Caribbean & Dominican Republic, Ecuador, El Salvador, Guatemala, Jamaica, \\
& Mexico, Panama, Peru, Uruguay, Venezuela \\
Middle East \& North Africa & Egypt, Iraq, Jordan, Lebanon, Morocco, Tunisia, Turkey \\
& Angola, Gabon, Ghana, Ivory Coast, Namibia, Nigeria, \\
Sub-Sahara Africa & Senegal, South Africa, Zambia \\
\hline
\end{tabular}

Table 3: Summary statistics of all variables

\begin{tabular}{|c|c|c|c|c|c|c|}
\hline & Obs. & Mean & Median & Std. Dev. & Min & Max \\
\hline$\Delta \mathrm{EMBI}$ & 10,006 & 0.686 & 0.729 & 3.921 & -16.23 & 13.47 \\
\hline$\Delta$ EMBI (regression sample) & 9,957 & 0.691 & 0.729 & 3.898 & -16.23 & 13.47 \\
\hline HistoricalTempAnomaly & 16,200 & 0.842 & 0.694 & 1.190 & -5.514 & 8.830 \\
\hline HistoricalTempAnomaly (regression sample) & 9,957 & 0.896 & 0.742 & 1.129 & -5.254 & 8.830 \\
\hline DeviationAdjustedTempAnomaly & 16,200 & 0.355 & 0.223 & 0.514 & -1.627 & 4.007 \\
\hline $\begin{array}{l}\text { DeviationAdjustedTempAnomaly } \\
\text { (regression sample) }\end{array}$ & 9,957 & 0.418 & 0.257 & 0.574 & -1.627 & 4.007 \\
\hline$\Delta$ Precipitation & 16,200 & 0.0960 & 0.0610 & 0.0971 & 0 & 1.072 \\
\hline$\Delta \mathrm{VIX}$ & 16,146 & 0.0656 & -0.0800 & 4.219 & -10.85 & 15.35 \\
\hline$\Delta$ GlobalGovernmentBondIndex & 16,146 & 0.367 & 0.307 & 1.817 & -4.967 & 5.365 \\
\hline$\Delta$ US-TermSpread & 16,146 & -0.00640 & -0.0430 & 0.272 & -0.551 & 0.800 \\
\hline$\Delta$ US-CorporateRiskPremium & 16,146 & 0.00347 & -0.0257 & 0.480 & -1.207 & 1.944 \\
\hline$\Delta$ US-10-YearTreasuryYield & 16,146 & -0.00858 & -0.0151 & 0.252 & -0.744 & 0.635 \\
\hline AgricultureToGDP & 16,032 & 10.36 & 8.300 & 6.952 & 2 & 38.96 \\
\hline ManufacturingToGDP & 15,624 & 14.85 & 15.09 & 5.688 & 0.650 & 35.01 \\
\hline ServicesToGDP & 16,032 & 51.42 & 52.65 & 9.533 & 10.57 & 75.85 \\
\hline ResourceRentsToGDP & 15,348 & 7.069 & 2.950 & 9.825 & 0 & 64.15 \\
\hline RuleOfLaw & 14,904 & 41.50 & 42.09 & 20.29 & 0 & 89.47 \\
\hline ControlOfCorruption & 14,904 & 41.88 & 42.55 & 21.25 & 0.510 & 91.88 \\
\hline CivilRights & 16,032 & 3.513 & 3 & 1.474 & 1 & 7 \\
\hline PoliticalRights & 16,044 & 3.426 & 3 & 1.933 & 1 & 7 \\
\hline ND-GAIN & 14,904 & 46.82 & 46.40 & 6.640 & 29.00 & 63.66 \\
\hline ReadinessIndex & 14,904 & 0.367 & 0.359 & 0.0899 & 0.133 & 0.613 \\
\hline VulnerabilityIndex & 14,904 & 0.431 & 0.419 & 0.0590 & 0.323 & 0.574 \\
\hline GDPPerCapita & 16,164 & 5,556 & 4,548 & 3,882 & 541.6 & 17,709 \\
\hline$\Delta$ EMBISpread & 9,694 & -0.589 & -2.406 & 80.76 & -310.2 & 371.9 \\
\hline$\Delta$ CDSSpread & 4,328 & 1.911 & -0.260 & 71.05 & -281.1 & 410.7 \\
\hline PoliticalStability & 14,904 & 38.72 & 38.37 & 21.91 & 0 & 93.75 \\
\hline$\Delta \mathrm{GDP}$ & 16,038 & 0.981 & 1.056 & 1.546 & -5.230 & 5.512 \\
\hline Drought & 16,200 & 0.0442 & 0 & 0.206 & 0 & 1 \\
\hline DroughtDamage & 16,200 & 0.0312 & 0 & 0.174 & 0 & 1 \\
\hline Earthquake & 16,200 & 0.0214 & 0 & 0.145 & 0 & 1 \\
\hline Flood & 16,200 & 0.114 & 0 & 0.318 & 0 & 1 \\
\hline Storm & 16,200 & 0.0496 & 0 & 0.217 & 0 & 1 \\
\hline Wildfire & 16,200 & 0.00815 & 0 & 0.0899 & 0 & 1 \\
\hline
\end{tabular}

Sample period is 1994:m1-2018:m12. Variables with $\Delta$ are in monthly growth rates and winsorized at the 1 st and 99th percentile, all other variables are in levels. See Table 18 for information on data sources. 
Table 4: Descriptive statistics on the connection between temperature, natural disasters, and economic performance

\begin{tabular}{lcccccc}
\hline & $\begin{array}{c}\text { Full Sample } \\
\text { Mean }\end{array}$ & Drought & $\begin{array}{c}\text { Droughts } \\
\text { with reported } \\
\text { Damage }\end{array}$ & Wildfire & Heat Wave $\begin{array}{r}\text { Cold Wave or } \\
\text { severe Winter }\end{array}$ \\
\hline Historical & 0.842 & 0.898 & 0.946 & 0.989 & 0.988 & 0.0623 \\
TempAnomaly & $(16,200)$ & $(716)$ & $(505)$ & $(132)$ & $(82)$ & $(269)$ \\
\hline
\end{tabular}

Mean of HistoricalTempAnomaly is shown for periods with occurring natural disasters in panel countries. Number of observations for each event is shown below in brackets.

\begin{tabular}{lccc}
\hline Economic Performance & Overall Mean & $\begin{array}{c}\text { Mean if Historical } \\
\text { Temperature Anomaly } \\
>75 \text { th percentile }\end{array}$ & $\begin{array}{c}\text { Mean if Historical } \\
\text { Temperature Anomaly } \\
<25 \text { th percentile }\end{array}$ \\
\hline $\begin{array}{l}\text { Stock Market Returns } \\
(38 \text { Countries) }\end{array}$ & 0.233 & -0.0872 & 0.412 \\
$\begin{array}{l}\text { Quarterly GDP Growth } \\
\text { full sample) } \\
\begin{array}{l}\text { Government Primary Surplus } \\
\text { in \% of GDP (42 Countries) }\end{array}\end{array}$ & 0.981 & 0.937 & 1.061 \\
\hline
\end{tabular}

Mean of an economic performance variable is shown over all periods, for periods with high temperature anomalies and for periods with low temperature anomalies. HistoricalTempAnomaly is on monthly frequency for stock returns ( 75 th percentile: $1.382^{\circ} \mathrm{C} ; 25$ th percentile: $0.286^{\circ} \mathrm{C}$ ), collapsed to quarterly frequency for GDP growth $\left(75\right.$ th percentile: $1.245^{\circ} \mathrm{C} ; 25$ th percentile: $0.321^{\circ} \mathrm{C}$ ), and collapsed to yearly frequency for government surplus ( 75 th percentile: $1.178^{\circ} \mathrm{C} ; 25$ th percentile: $0.447^{\circ} \mathrm{C}$ ) to match the respective frequency. 
Table 5: Countries in each percentile- or $5^{\circ} \mathrm{C}$-interval-defined climatic bin

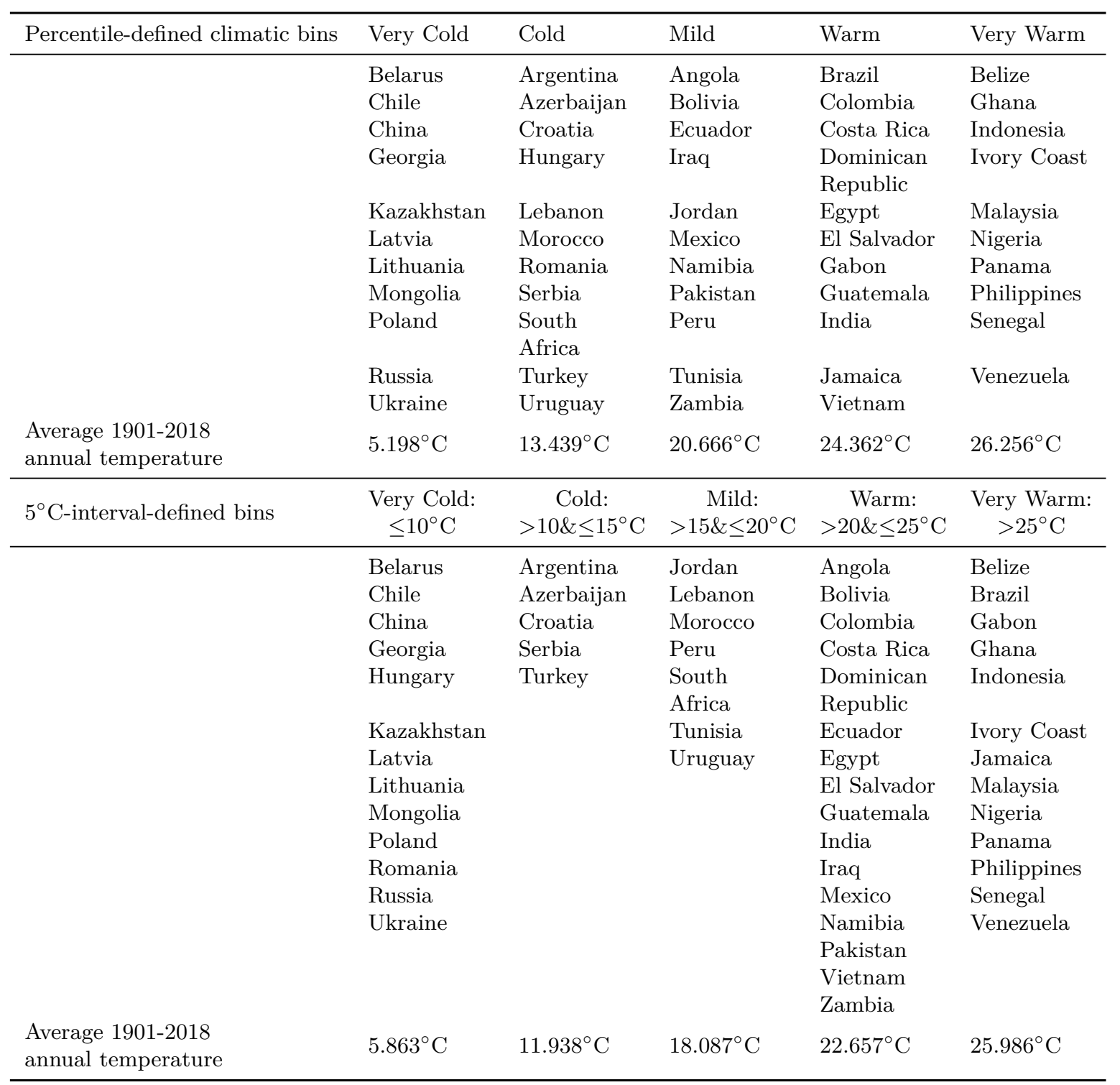


Table 6: Baseline results: temperature anomalies and sovereign risk

\begin{tabular}{|c|c|c|c|c|c|c|}
\hline & $\begin{array}{c}(1) \\
\Delta \mathrm{EMBI}\end{array}$ & $\begin{array}{c}(2) \\
\Delta \mathrm{EMBI}\end{array}$ & $\begin{array}{c}(3) \\
\Delta \mathrm{EMBI}\end{array}$ & $\begin{array}{c}(4) \\
\Delta \mathrm{EMBI}\end{array}$ & $\begin{array}{c}(5) \\
\Delta \mathrm{EMBI}\end{array}$ & $\begin{array}{c}(6) \\
\Delta \mathrm{EMBI}\end{array}$ \\
\hline HistoricalTempAnomaly & $\begin{array}{c}-0.0614^{* *} \\
(0.0267)\end{array}$ & $\begin{array}{c}-0.0798^{* * *} \\
(0.0269)\end{array}$ & $\begin{array}{l}-0.0118 \\
(0.0507)\end{array}$ & & & \\
\hline DeviationAdjustedTempAnomaly & & & & $\begin{array}{c}-0.219^{* * *} \\
(0.0681)\end{array}$ & $\begin{array}{c}-0.233^{* * *} \\
(0.0633)\end{array}$ & $\begin{array}{c}-0.235^{* * *} \\
(0.0798)\end{array}$ \\
\hline Precipitation & & $\begin{array}{c}0.197 \\
(0.416)\end{array}$ & $\begin{array}{c}0.223 \\
(0.363)\end{array}$ & & $\begin{array}{c}0.110 \\
(0.424)\end{array}$ & $\begin{array}{l}0.0385 \\
(0.375)\end{array}$ \\
\hline$\Delta \mathrm{VIX}$ & & $\begin{array}{c}-0.151^{* * *} \\
(0.0164)\end{array}$ & & & $\begin{array}{c}-0.151^{* * *} \\
(0.0164)\end{array}$ & \\
\hline$\Delta$ GlobalGovernmentBondIndex & & $\begin{array}{c}0.0691^{*} \\
(0.0370)\end{array}$ & & & $\begin{array}{c}0.0690^{*} \\
(0.0370)\end{array}$ & \\
\hline$\Delta \mathrm{US}$-TermSpread & & $\begin{array}{l}-0.102 \\
(0.199)\end{array}$ & & & $\begin{array}{l}-0.106 \\
(0.199)\end{array}$ & \\
\hline$\Delta$ US-CorporateRiskPremium & & $\begin{array}{c}-2.445^{* * *} \\
(0.186)\end{array}$ & & & $\begin{array}{c}-2.443^{* * *} \\
(0.186)\end{array}$ & \\
\hline$\Delta$ US-10-YearTreasuryYield & & $\begin{array}{c}-3.689^{* * *} \\
(0.437)\end{array}$ & & & $\begin{array}{c}-3.684^{* * *} \\
(0.438)\end{array}$ & \\
\hline Constant & $\begin{array}{c}0.740^{* * *} \\
(0.0239)\end{array}$ & $\begin{array}{c}0.688^{* * *} \\
(0.0539)\end{array}$ & $\begin{array}{c}0.679 * * * \\
(0.0631)\end{array}$ & $\begin{array}{c}0.777^{* * *} \\
(0.0284)\end{array}$ & $\begin{array}{c}0.722^{* * *} \\
(0.0560)\end{array}$ & $\begin{array}{c}0.786^{* * *} \\
(0.0552)\end{array}$ \\
\hline Observations & 10,006 & 10,006 & 9,957 & 10,006 & 10,006 & 9,957 \\
\hline R-squared & 0.068 & 0.217 & 0.524 & 0.068 & 0.218 & 0.524 \\
\hline Country FE & Yes & Yes & Yes & Yes & Yes & Yes \\
\hline Region $\times$ Year FE & Yes & Yes & No & Yes & Yes & No \\
\hline Region $\times$ MonthYear FE & No & No & Yes & No & No & Yes \\
\hline
\end{tabular}

This table shows OLS estimation results of a panel of 54 countries from $1994 \mathrm{~m} 1$ to $2018 \mathrm{~m} 12$. $\Delta \mathrm{EMBI}$ are monthly natural log returns of a country's EMBI index. HistoricalTempAnomaly is the difference between monthly temperature of a country and its 1901-1950 temperature average of the same month. DeviationAdjustedTempAnomaly is the anomaly measure divided by a country's 1901-1950 average of temperature standard deviation. Precipitation is the country-specific average in $1000 \mathrm{~mm}$ units. $\Delta$ VIX, $\Delta$ US-TermSpread (10-year treasury yield minus 3-month T-Bill yield), $\Delta$ US-CorporateRiskPremium (high corporate bond yield minus investment grade corporate bond yield) and $\Delta$ US-10-YearTreasuryYield are in simple first differences, $\Delta$ GlobalGovernmentBondIndex is in natural log differences. Standard errors (in parentheses) are clustered at the country level, ${ }^{* * *},{ }^{* *}$ and $*$ indicate statistical significance at the $1 \%, 5 \%$ and $10 \%$ level, respectively. See Table 18 for variable definitions and sources. 
Table 7: Channels of temperature-sovereign risk connection: general warmness

\begin{tabular}{|c|c|c|}
\hline & $\begin{array}{c}(1) \\
\Delta \mathrm{EMBI}\end{array}$ & $\begin{array}{c}(2) \\
\Delta \mathrm{EMBI}\end{array}$ \\
\hline HistoricalTempAnomaly & $\begin{array}{c}0.0596 \\
(0.0834)\end{array}$ & $\begin{array}{l}0.0825 \\
(0.117)\end{array}$ \\
\hline VeryColdCountry $($ percentile $) \times$ HistoricalTempAnomaly & $\begin{array}{l}-0.0731 \\
(0.0802)\end{array}$ & \\
\hline ColdCountry (percentile; base category) $\times$ HistoricalTempAnomaly & $\begin{array}{c}0 \\
(0)\end{array}$ & \\
\hline MildCountry $($ percentile $) \times$ HistoricalTempAnomaly & $\begin{array}{r}-0.0639 \\
(0.114)\end{array}$ & \\
\hline WarmCountry (percentile) × HistoricalTempAnomaly & $\begin{array}{l}-0.224 \\
(0.174)\end{array}$ & \\
\hline VeryWarmCountry $($ percentile $) \times$ HistoricalTempAnomaly & $\begin{array}{c}-0.491^{* *} \\
(0.233)\end{array}$ & \\
\hline VeryColdCountry $\left(\leq 10^{\circ} \mathrm{C}\right) \times$ HistoricalTempAnomaly & & $\begin{array}{r}-0.0492 \\
(0.110)\end{array}$ \\
\hline ColdCountry $\left(>10 \& \leq 15^{\circ} \mathrm{C}\right.$; base category $) \times$ HistoricalTempAnomaly & & $\begin{array}{c}0 \\
(0)\end{array}$ \\
\hline MildCountry $\left(>15 \& \leq 20^{\circ} \mathrm{C}\right) \times$ HistoricalTempAnomaly & & $\begin{array}{l}-0.207 \\
(0.124)\end{array}$ \\
\hline WarmCountry $\left(>20 \& \leq 25^{\circ} \mathrm{C}\right) \times$ HistoricalTempAnomaly & & $\begin{array}{l}-0.125 \\
(0.155)\end{array}$ \\
\hline VeryWarmCountry $\left(>25^{\circ} \mathrm{C}\right) \times$ HistoricalTempAnomaly & & $\begin{array}{c}-0.547^{* *} \\
(0.229)\end{array}$ \\
\hline Precipitation & $\begin{array}{l}0.0640 \\
(0.406)\end{array}$ & $\begin{array}{c}0.00819 \\
(0.393)\end{array}$ \\
\hline Observations & 9,957 & 9,957 \\
\hline R-squared & 0.524 & 0.524 \\
\hline Country FE & Yes & Yes \\
\hline Region $\times$ MonthYear FE & Yes & Yes \\
\hline Total "very warm" Country Effect & -0.432 & -0.464 \\
\hline \multicolumn{3}{|c|}{$\begin{array}{l}\text { This table shows OLS estimation results of a panel of } 54 \text { countries from } 1994 \mathrm{~m} 1 \text { to } 2018 \mathrm{~m} 12 . \Delta \mathrm{EMBI} \\
\text { are monthly natural log returns of a country's EMBI index. HistoricalTempAnomaly is the difference } \\
\text { between monthly temperature of a country and its } 1901-1950 \text { temperature average of the same month. } \\
\text { Each country is grouped into a bin either according to percentiles (see Table } 5 \text { for respective countries) } \\
\text { or } 5^{\circ} \mathrm{C} \text { intervals (see Table ?? for respective countries). One bin is omitted due to multicollinearity (base } \\
\text { category). Single terms of the bins are subsumed by time fixed effects. Total "very warm" country effect } \\
\text { is the sum of the VeryWarmCountry interaction and the single term of HistoricalTempAnomaly. Standard } \\
\text { errors (in parentheses) are clustered at the country level, } * * *, * * \text { and } * \text { indicate statistical significance at } \\
\text { the } 1 \%, 5 \% \text { and } 10 \% \text { level, respectively. See Table } 18 \text { for variable definitions and sources. }\end{array}$} \\
\hline
\end{tabular}




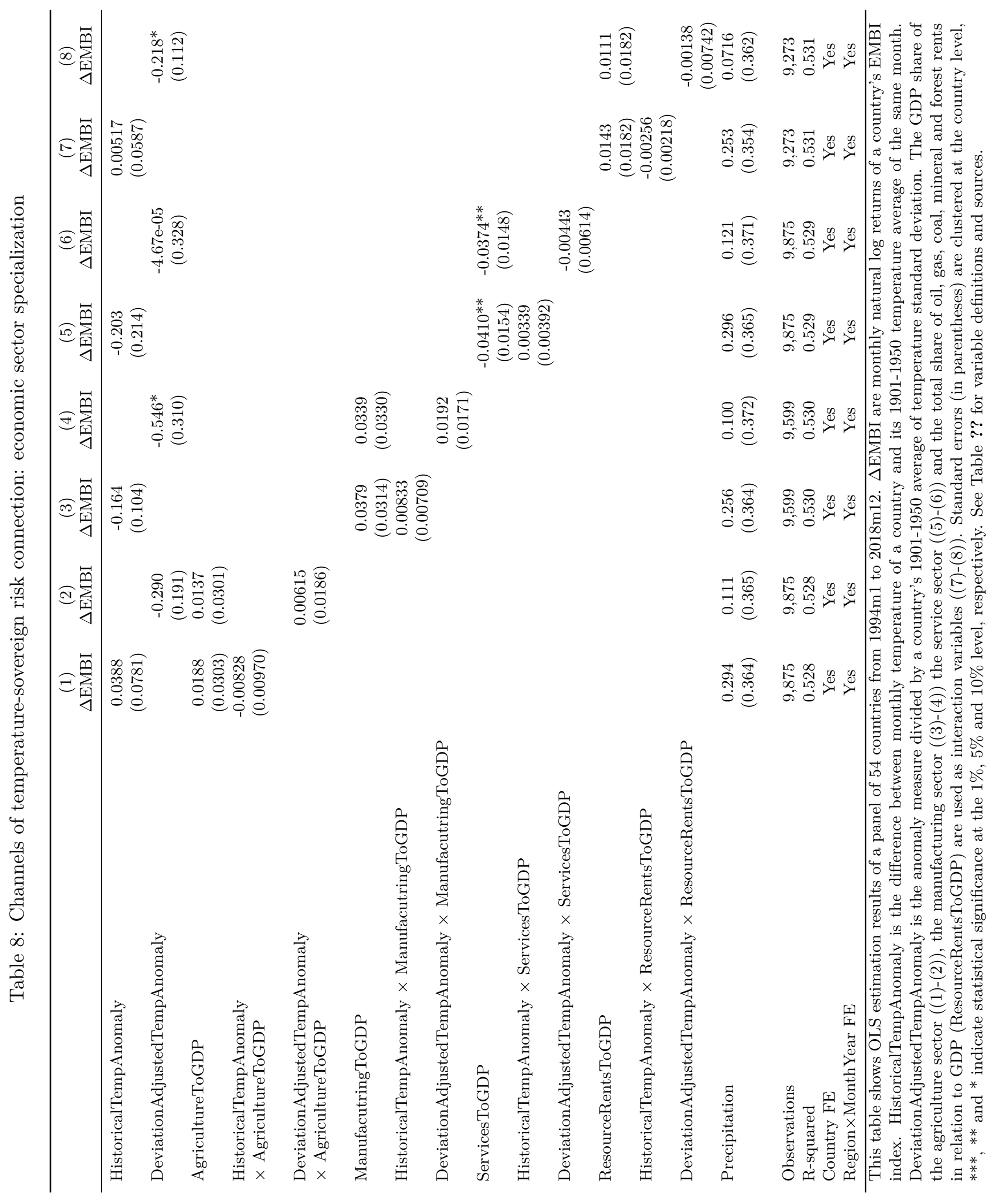




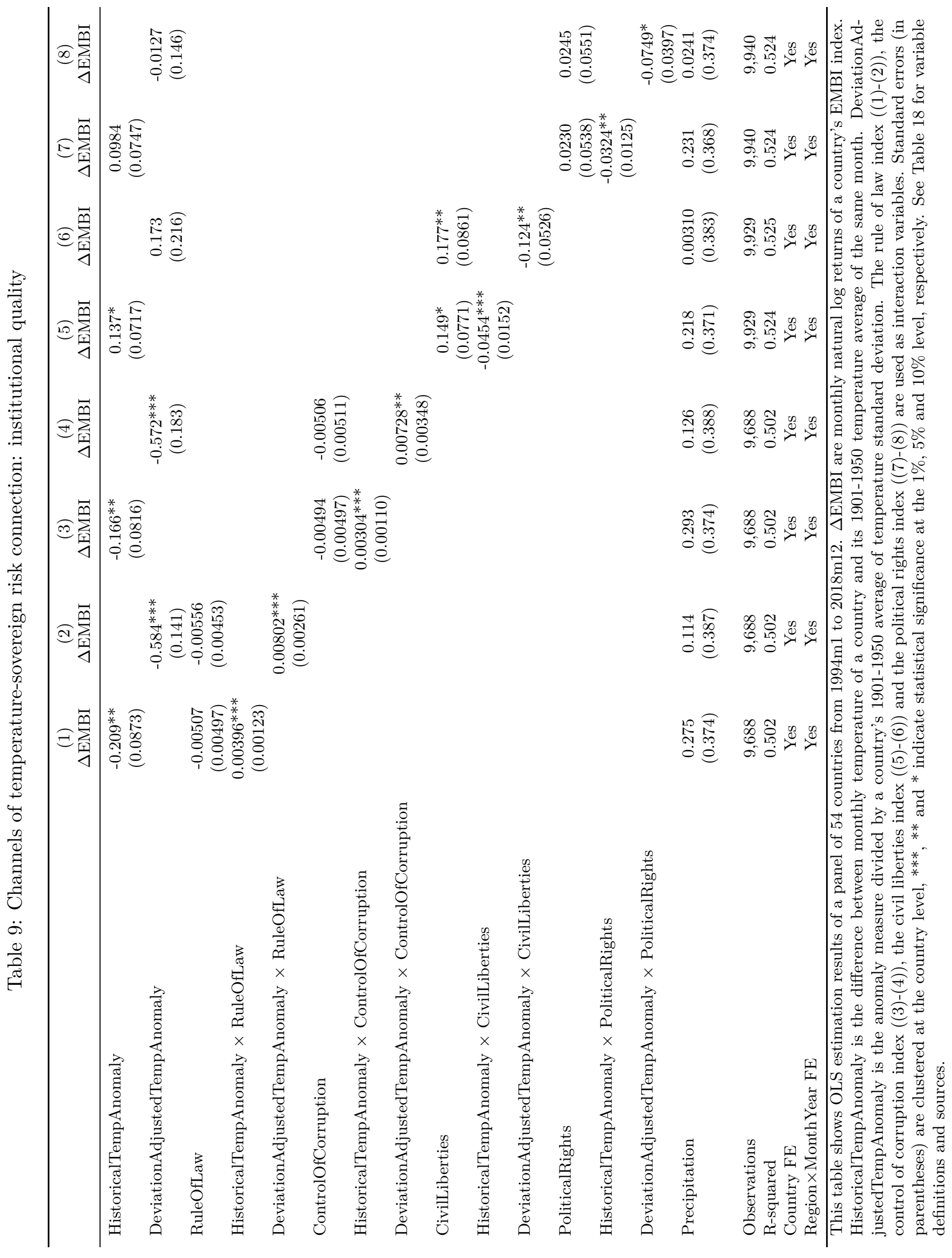


Table 10: Channels of temperature-sovereign risk connection: climate-related institutional quality

\begin{tabular}{|c|c|c|c|c|c|c|}
\hline & $\begin{array}{c}(1) \\
\Delta \mathrm{EMBI}\end{array}$ & $\begin{array}{c}(2) \\
\Delta \mathrm{EMBI}\end{array}$ & $\begin{array}{c}(3) \\
\Delta \mathrm{EMBI}\end{array}$ & $\begin{array}{c}(4) \\
\Delta \mathrm{EMBI}\end{array}$ & $\begin{array}{c}(5) \\
\Delta \mathrm{EMBI}\end{array}$ & $\begin{array}{c}(6) \\
\Delta \mathrm{EMBI}\end{array}$ \\
\hline HistoricalTempAnomaly & $\begin{array}{c}-0.703^{*} \\
(0.354)\end{array}$ & & $\begin{array}{c}-0.506^{* * *} \\
(0.179)\end{array}$ & & $\begin{array}{c}0.144 \\
(0.359)\end{array}$ & \\
\hline DeviationAdjustedTempAnomaly & & $\begin{array}{c}-1.684^{* *} \\
(0.750)\end{array}$ & & $\begin{array}{c}-1.239 * * * \\
(0.322)\end{array}$ & & $\begin{array}{l}-0.523 \\
(0.803)\end{array}$ \\
\hline ND-GAIN & $\begin{array}{l}-0.0531 \\
(0.0441)\end{array}$ & $\begin{array}{l}-0.0551 \\
(0.0398)\end{array}$ & & & & \\
\hline $\begin{array}{l}\text { HistoricalTempAnomaly } \\
\times \text { ND-GAIN }\end{array}$ & $\begin{array}{l}0.0129 * \\
(0.00651)\end{array}$ & & & & & \\
\hline $\begin{array}{l}\text { DeviationAdjustedTempAnomaly } \\
\times \text { ND-GAIN }\end{array}$ & & $\begin{array}{l}0.0301^{*} \\
(0.0152)\end{array}$ & & & & \\
\hline ReadinessIndex & & & $\begin{array}{l}-2.813 \\
(2.044)\end{array}$ & $\begin{array}{l}-3.190^{*} \\
(1.789)\end{array}$ & & \\
\hline $\begin{array}{l}\text { HistoricalTempAnomaly } \\
\times \text { ReadinessIndex }\end{array}$ & & & $\begin{array}{l}1.081^{* * *} \\
(0.367)\end{array}$ & & & \\
\hline $\begin{array}{l}\text { DeviationAdjustedTempAnomaly } \\
\times \text { ReadinessIndex }\end{array}$ & & & & $\begin{array}{l}2.636^{* * *} \\
(0.830)\end{array}$ & & \\
\hline VulnerabilityIndex & & & & & $\begin{array}{l}13.17 \\
(12.11)\end{array}$ & $\begin{array}{c}13.15 \\
(11.89)\end{array}$ \\
\hline $\begin{array}{l}\text { HistoricalTempAnomaly } \\
\times \text { VulnerabilityIndex }\end{array}$ & & & & & $\begin{array}{l}-0.432 \\
(0.913)\end{array}$ & \\
\hline $\begin{array}{l}\text { DeviationAdjustedTempAnomaly } \\
\times \text { VulnerabilityIndex }\end{array}$ & & & & & & $\begin{array}{l}0.614 \\
(1.903)\end{array}$ \\
\hline Precipitation & $\begin{array}{c}0.301 \\
(0.373)\end{array}$ & $\begin{array}{c}0.193 \\
(0.390)\end{array}$ & $\begin{array}{c}0.291 \\
(0.372)\end{array}$ & $\begin{array}{c}0.174 \\
(0.395)\end{array}$ & $\begin{array}{c}0.362 \\
(0.366)\end{array}$ & $\begin{array}{c}0.180 \\
(0.381)\end{array}$ \\
\hline Observations & 9,842 & 9,842 & 9,842 & 9,842 & 9,842 & 9,842 \\
\hline R-squared & 0.510 & 0.511 & 0.510 & 0.511 & 0.510 & 0.510 \\
\hline Country FE & Yes & Yes & Yes & Yes & Yes & Yes \\
\hline Region $\times$ MonthYear FE & Yes & Yes & Yes & Yes & Yes & Yes \\
\hline
\end{tabular}

This table shows OLS estimation results of a panel of 54 countries from $1994 \mathrm{~m} 1$ to $2018 \mathrm{~m} 12 . \Delta \mathrm{EMBI}$ are monthly natural log returns of a country's EMBI index. HistoricalTempAnomaly is the difference between monthly temperature of a country and its 1901-1950 temperature average of the same month. DeviationAdjustedTempAnomaly is the anomaly measure divided by a country's 1901-1950 average of temperature standard deviation. The Notre Dame Global Adaption Index (ND-GAIN) ((1)-(2)), the readiness component of the ND-GAIN ((3)-(4)) and vulnerability component of the ND-GAIN ((5)-(6)) are used as interaction variables. Standard errors (in parentheses) are clustered at the country level, ***, ** and $*$ indicate statistical significance at the $1 \%, 5 \%$ and $10 \%$ level, respectively. See Table 18 for variable definitions and sources. 
Table 11: Channels of temperature-sovereign risk connection: combining relevant channels

\begin{tabular}{|c|c|c|c|c|}
\hline & $\begin{array}{c}(1) \\
\Delta \mathrm{EMBI}\end{array}$ & $\begin{array}{c}(2) \\
\Delta \mathrm{EMBI}\end{array}$ & $\begin{array}{c}(3) \\
\Delta \mathrm{EMBI}\end{array}$ & $\begin{array}{c}(4) \\
\Delta \mathrm{EMBI}\end{array}$ \\
\hline HistoricalTempAnomaly & $\begin{array}{l}-0.145^{*} \\
(0.0764)\end{array}$ & $\begin{array}{c}-0.233^{* * *} \\
(0.0845)\end{array}$ & $\begin{array}{l}-0.151^{*} \\
(0.0893)\end{array}$ & $\begin{array}{l}-0.137 \\
(0.137)\end{array}$ \\
\hline GDPPerCapita & $\begin{array}{l}-5.83 \mathrm{e}-05 \\
(4.14 \mathrm{e}-05)\end{array}$ & $\begin{array}{l}-4.19 \mathrm{e}-05 \\
(4.06 \mathrm{e}-05)\end{array}$ & $\begin{array}{l}-4.04 \mathrm{e}-05 \\
(4.03 \mathrm{e}-05)\end{array}$ & $\begin{array}{l}-3.57 \mathrm{e}-05 \\
(3.98 \mathrm{e}-05)\end{array}$ \\
\hline $\begin{array}{l}\text { HistoricalTempAnomaly } \\
\times \text { GDPPerCapita }\end{array}$ & $\begin{array}{l}1.70 \mathrm{e}-05^{* *} \\
(6.54 \mathrm{e}-06)\end{array}$ & $\begin{array}{l}7.21 \mathrm{e}-06 \\
(7.80 \mathrm{e}-06)\end{array}$ & $\begin{array}{l}5.97 \mathrm{e}-06 \\
(7.54 \mathrm{e}-06)\end{array}$ & $\begin{array}{l}2.71 \mathrm{e}-06 \\
(6.80 \mathrm{e}-06)\end{array}$ \\
\hline RuleOfLaw & & $\begin{array}{l}-0.00315 \\
(0.00477)\end{array}$ & $\begin{array}{l}-0.00235 \\
(0.00474)\end{array}$ & $\begin{array}{l}-0.00414 \\
(0.00467)\end{array}$ \\
\hline HistoricalTempAnomaly $\times$ RuleOfLaw & & $\begin{array}{c}0.00326^{* *} \\
(0.00149)\end{array}$ & $\begin{array}{c}0.00317^{* *} \\
(0.00138)\end{array}$ & $\begin{array}{c}0.00381^{* * *} \\
(0.00133)\end{array}$ \\
\hline DeviationAdjustedTempAnomaly & & & $\begin{array}{c}-0.314^{* * *} \\
(0.107)\end{array}$ & \\
\hline $\begin{array}{l}\text { VeryColdCountry }\left(\leq 10^{\circ} \mathrm{C}\right) \\
\times \text { HistoricalTempAnomaly }\end{array}$ & & & & $\begin{array}{r}-0.0508 \\
(0.101)\end{array}$ \\
\hline $\begin{array}{l}\text { ColdCountry ( }>10 \& \leq 15^{\circ} \mathrm{C} \text {; base category) } \\
\times \text { HistoricalTempAnomaly }\end{array}$ & & & & $\begin{array}{l}0 \\
(0)\end{array}$ \\
\hline $\begin{array}{l}\text { MildCountry }\left(>15 \& \leq 20^{\circ} \mathrm{C}\right) \mathrm{c} \\
\times \text { HistoricalTempAnomaly }\end{array}$ & & & & $\begin{array}{l}-0.217 \\
(0.131)\end{array}$ \\
\hline $\begin{array}{l}\text { WarmCountry }\left(>20 \& \leq 25^{\circ} \mathrm{C}\right) \\
\times \text { HistoricalTempAnomaly }\end{array}$ & & & & $\begin{array}{l}-0.0422 \\
(0.158)\end{array}$ \\
\hline $\begin{array}{l}\text { VeryWarmCountry }\left(>25^{\circ} \mathrm{C}\right) \\
\times \text { HistoricalTempAnomaly }\end{array}$ & & & & $\begin{array}{l}-0.539^{* *} \\
(0.237)\end{array}$ \\
\hline Precipitation & $\begin{array}{c}0.194 \\
(0.367)\end{array}$ & $\begin{array}{l}0.267 \\
(0.375)\end{array}$ & $\begin{array}{l}0.0751 \\
(0.387)\end{array}$ & $\begin{array}{l}0.0683 \\
(0.392)\end{array}$ \\
\hline Observations & 9,957 & 9,688 & 9,688 & 9,688 \\
\hline R-squared & 0.524 & 0.502 & 0.502 & 0.502 \\
\hline Country FE & Yes & Yes & Yes & Yes \\
\hline Region $\times$ MonthYear FE & Yes & Yes & Yes & Yes \\
\hline \multicolumn{5}{|c|}{$\begin{array}{l}\text { This table shows OLS estimation results of a panel of } 54 \text { countries from } 1994 \mathrm{~m} 1 \text { to } 2018 \mathrm{~m} 12 . \Delta \text { EMBI } \\
\text { are monthly natural log returns of a country's EMBI index. HistoricalTempAnomaly is the difference } \\
\text { between monthly temperature of a country and its } 1901-1950 \text { temperature average of the same month. } \\
\text { DeviationAdjustedTempAnomaly is the anomaly measure divided by a country's } 1901-1950 \text { average of } \\
\text { temperature standard deviation. GDP per capita }((1)-(4)) \text { and rule of law }((2)-(4)) \text { are used as interaction } \\
\text { variables. Standard errors (in parentheses) are clustered at the country level, ***, ** and * indicate } \\
\text { statistical significance at the } 1 \%, 5 \% \text { and } 10 \% \text { level, respectively. See Table } 18 \text { for variable definitions and } \\
\text { sources. }\end{array}$} \\
\hline
\end{tabular}




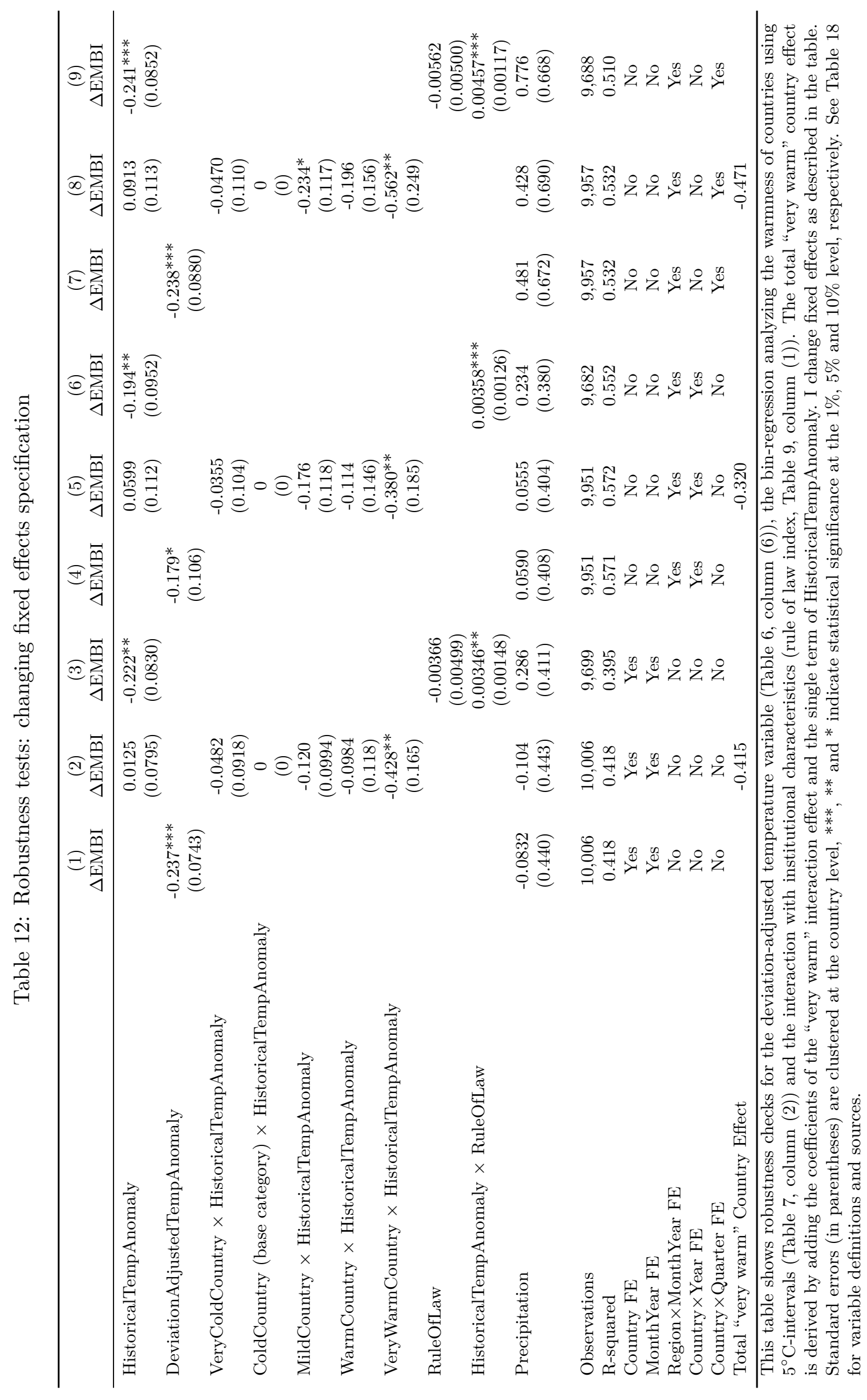


Table 13: Robustness tests: changing dependent variable

\begin{tabular}{|c|c|c|c|c|c|}
\hline & $\begin{array}{c}(1) \\
\Delta \text { EMBI } \\
\text { Spread }\end{array}$ & $\begin{array}{c}(2) \\
\Delta \text { EMBI } \\
\text { Spread }\end{array}$ & $\begin{array}{c}(3) \\
\Delta \text { EMBI } \\
\text { Spread }\end{array}$ & $\begin{array}{c}(4) \\
\Delta \mathrm{CDS} \\
\text { Spread }\end{array}$ & $\begin{array}{c}(5) \\
\Delta \mathrm{CDS} \\
\text { Spread }\end{array}$ \\
\hline DeviationAdjustedTempAnomaly & $\begin{array}{l}3.667^{*} \\
(1.837)\end{array}$ & & & $\begin{array}{l}8.276 \\
(5.990)\end{array}$ & \\
\hline HistoricalTempAnomaly & & $\begin{array}{l}-1.649 \\
(2.248)\end{array}$ & $\begin{array}{l}4.776^{* *} \\
(2.287)\end{array}$ & & $\begin{array}{c}11.17^{* *} \\
(4.513)\end{array}$ \\
\hline $\begin{array}{l}\text { VeryColdCountry } \\
\times \text { HistoricalTempAnomaly }\end{array}$ & & $\begin{array}{l}1.354 \\
(2.182)\end{array}$ & & & \\
\hline $\begin{array}{l}\text { ColdCountry (base category) } \\
\times \text { HistoricalTempAnomaly }\end{array}$ & & $\begin{array}{l}0 \\
(0)\end{array}$ & & & \\
\hline $\begin{array}{l}\text { MildCountry } \\
\times \text { HistoricalTempAnomaly }\end{array}$ & & $\begin{array}{l}3.301 \\
(2.208)\end{array}$ & & & \\
\hline $\begin{array}{l}\text { WarmCountry } \\
\times \text { HistoricalTempAnomaly }\end{array}$ & & $\begin{array}{l}1.766 \\
(2.580)\end{array}$ & & & \\
\hline $\begin{array}{l}\text { VeryWarmCountry } \\
\times \text { HistoricalTempAnomaly }\end{array}$ & & $\begin{array}{l}11.27^{*} \\
(5.734)\end{array}$ & & & \\
\hline RuleOfLaw & & & $\begin{array}{r}-0.0610 \\
(0.146)\end{array}$ & & $\begin{array}{r}-0.0811 \\
(0.217)\end{array}$ \\
\hline $\begin{array}{l}\text { HistoricalTempAnomaly } \\
\times \text { RuleOfLaw }\end{array}$ & & & $\begin{array}{l}-0.0940^{* * *} \\
(0.0350)\end{array}$ & & $\begin{array}{l}-0.187^{* *} \\
(0.0744)\end{array}$ \\
\hline Precipitation & $\begin{array}{l}-14.57^{*} \\
(8.247)\end{array}$ & $\begin{array}{l}-13.10 \\
(8.715)\end{array}$ & $\begin{array}{l}-15.86^{*} \\
(8.030)\end{array}$ & $\begin{array}{c}19.17 \\
(18.99)\end{array}$ & $\begin{array}{c}15.03 \\
(15.71)\end{array}$ \\
\hline Observations & 9,610 & 9,610 & 9,491 & 4,277 & 4,277 \\
\hline R-squared & 0.463 & 0.464 & 0.456 & 0.349 & 0.351 \\
\hline Number of Countries & 54 & 54 & 54 & 37 & 37 \\
\hline Country FE & Yes & Yes & Yes & Yes & Yes \\
\hline Region $\times$ MonthYear FE & Yes & Yes & Yes & Yes & Yes \\
\hline
\end{tabular}

This table shows robustness checks for the deviation-adjusted temperature variable (Table 6, column (6)), the bin-regression analyzing the warmness of countries using $5^{\circ} \mathrm{C}$-intervals (Table 7 , column (2)) and the interaction with institutional characteristics (rule of law index, Table 9, column (1)). Columns (1)-(3) use the first difference of the EMBI spread, and columns (4)-(5) the first difference of the CDS spread as a new dependent variable. Standard errors (in parentheses) are clustered at the country level, ${ }^{* * *},{ }^{* *}$ and $*$ indicate statistical significance at the $1 \%, 5 \%$ and $10 \%$ level, respectively. See Table 18 for variable definitions and sources. 


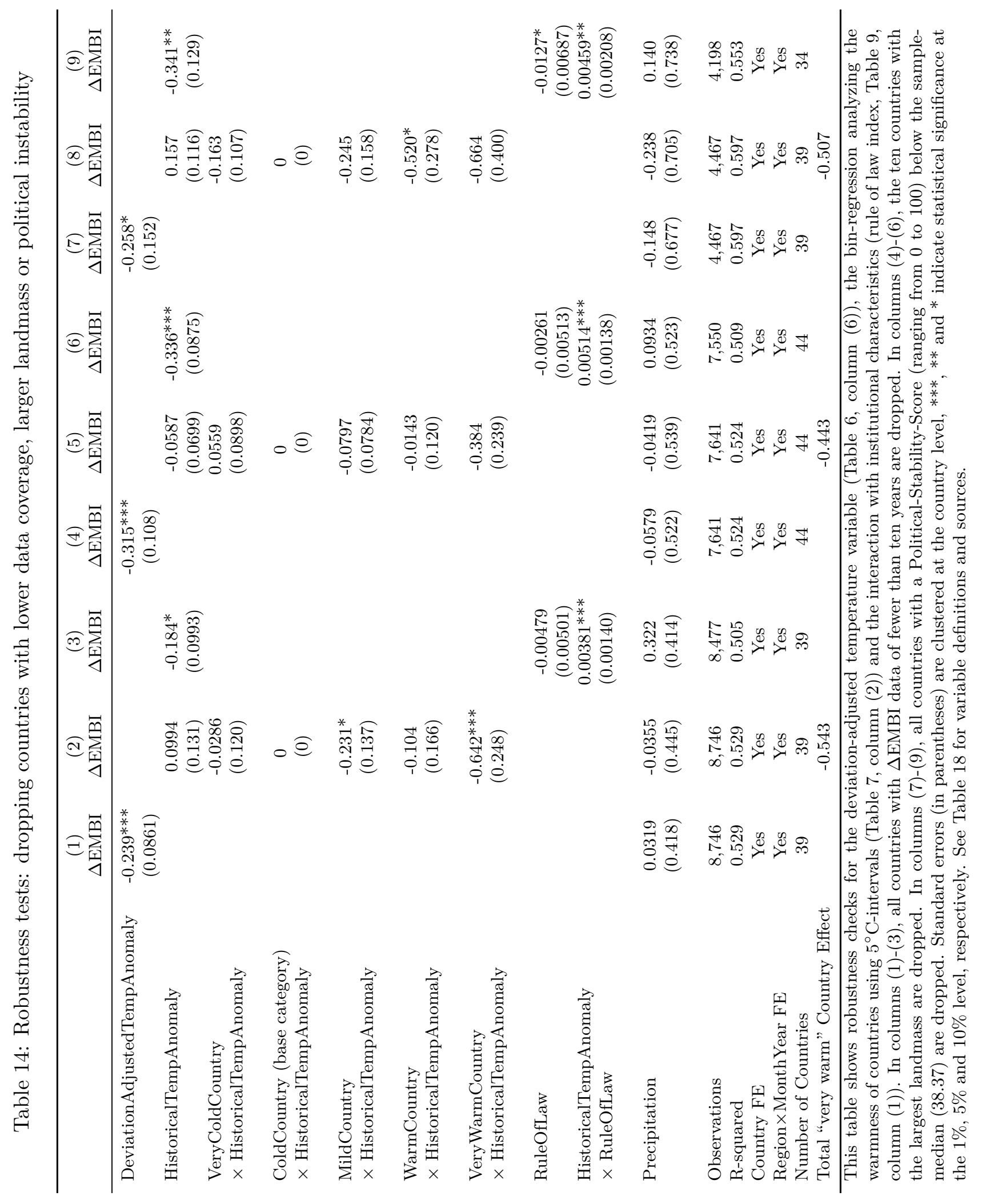


Table 15: Robustness tests: Paris Agreement as transition shock

\begin{tabular}{|c|c|c|c|c|}
\hline & $\begin{array}{c}(1) \\
\Delta \mathrm{EMBI}\end{array}$ & $\begin{array}{c}(2) \\
\Delta \mathrm{EMBI}\end{array}$ & $\begin{array}{c}(3) \\
\Delta \mathrm{EMBI}\end{array}$ & $\begin{array}{c}(4) \\
\Delta \mathrm{EMBI}\end{array}$ \\
\hline HistoricalTempAnomaly & $\begin{array}{l}-0.00387 \\
(0.0608)\end{array}$ & & $\begin{array}{l}0.0963 \\
(0.147)\end{array}$ & $\begin{array}{c}-0.211^{* *} \\
(0.104)\end{array}$ \\
\hline HistoricalTempAnomaly $\times$ PostParis & $\begin{array}{l}-0.0363 \\
(0.0651)\end{array}$ & & $\begin{array}{r}-0.0631 \\
(0.159)\end{array}$ & $\begin{array}{l}0.0255 \\
(0.129)\end{array}$ \\
\hline DeviationAdjustedTempAnomaly & & $\begin{array}{c}-0.246^{* * *} \\
(0.0873)\end{array}$ & & \\
\hline DeviationAdjustedTempAnomaly $\times$ PostParis & & $\begin{array}{c}0.0522 \\
(0.0843)\end{array}$ & & \\
\hline HistoricalTempAnomaly $\times$ VeryWarmCountry & & & $\begin{array}{c}-0.608^{* *} \\
(0.257)\end{array}$ & \\
\hline VeryWarmCountry $\times$ PostParis & & & $\begin{array}{l}-0.335 \\
(0.430)\end{array}$ & \\
\hline HistoricalTempAnomaly $\times$ VeryWarmCountry $\times$ PostParis & & & $\begin{array}{c}0.375 \\
(0.340)\end{array}$ & \\
\hline RuleOfLaw & & & & $\begin{array}{l}-0.00551 \\
(0.00504)\end{array}$ \\
\hline HistoricalTempAnomaly $\times$ RuleOfLaw & & & & $\begin{array}{c}0.00415^{* * *} \\
(0.00146)\end{array}$ \\
\hline RuleOfLaw $\times$ PostParis & & & & $\begin{array}{c}0.00255 \\
(0.00374)\end{array}$ \\
\hline HistoricalTempAnomaly $\times$ RuleOfLaw $\times$ PostParis & & & & $\begin{array}{l}-0.00113 \\
(0.00207)\end{array}$ \\
\hline Precipitation & $\begin{array}{c}0.224 \\
(0.363)\end{array}$ & $\begin{array}{l}0.0364 \\
(0.376)\end{array}$ & $\begin{array}{l}0.0261 \\
(0.398)\end{array}$ & $\begin{array}{c}0.274 \\
(0.374)\end{array}$ \\
\hline Observations & 9,957 & 9,957 & 9,957 & 9,688 \\
\hline R-squared & 0.524 & 0.524 & 0.525 & 0.502 \\
\hline Country FE & Yes & Yes & Yes & Yes \\
\hline Region $\times$ MonthYear FE & Yes & Yes & Yes & Yes \\
\hline Other Bin Terms & & & Yes & \\
\hline
\end{tabular}

This table shows robustness checks for the temperature anomaly measure (Table 6, column (3)), the deviation-adjusted temperature variable (Table 6, column (6)), the bin-regression analyzing the warmness of countries using $5^{\circ} \mathrm{C}$-intervals (Table 7 , column (2)) and the interaction with institutional characteristics (rule of law index, Table 9, column (1)). PostParis is a dummy with value 1 after the Paris Climate Agreement in December 2015. Estimation in column (3) also includes all other bin categories (cold as base category) and respective interactions. Standard errors (in parentheses) are clustered at the country level, $* * *, * *$ and $*$ indicate statistical significance at the $1 \%, 5 \%$ and $10 \%$ level, respectively. See Table 18 for variable definitions and sources. 
Table 16: Robustness tests: impact of natural disasters on GDP Growth

\begin{tabular}{|c|c|c|c|c|c|c|}
\hline & $\begin{array}{c}(1) \\
\Delta \mathrm{GDP}\end{array}$ & $\begin{array}{c}(2) \\
\Delta \mathrm{GDP}\end{array}$ & $\begin{array}{c}(3) \\
\Delta \mathrm{GDP}\end{array}$ & $\begin{array}{c}(4) \\
\Delta \mathrm{GDP}\end{array}$ & $\begin{array}{c}(5) \\
\Delta \mathrm{GDP}\end{array}$ & $\begin{array}{c}(6) \\
\Delta \mathrm{GDP}\end{array}$ \\
\hline Drought & $\begin{array}{l}0.0588 \\
(0.157)\end{array}$ & & & & & \\
\hline VeryWarmCountry $\times$ Drought & $\begin{array}{l}-0.685^{*} \\
(0.367)\end{array}$ & & & & & \\
\hline DroughtDamage & & $\begin{array}{c}0.133 \\
(0.182)\end{array}$ & & & & \\
\hline VeryWarmCountry $\times$ DroughtDamage & & $\begin{array}{c}-0.958^{* * *} \\
(0.358)\end{array}$ & & & & \\
\hline Wildfire & & & $\begin{array}{l}-0.388 \\
(0.531)\end{array}$ & & & \\
\hline VeryWarmCountry $\times$ Wildfire & & & $\begin{array}{c}-2.831^{* * *} \\
(0.832)\end{array}$ & & & \\
\hline Flood & & & & $\begin{array}{l}-0.111 \\
(0.262)\end{array}$ & & \\
\hline VeryWarmCountry $\times$ Flood & & & & $\begin{array}{c}0.576 \\
(0.500)\end{array}$ & & \\
\hline Storm & & & & & $\begin{array}{l}-0.259 \\
(0.510)\end{array}$ & \\
\hline VeryWarmCountry $\times$ Storm & & & & & $\begin{array}{l}1.402^{*} \\
(0.820)\end{array}$ & \\
\hline Earthquake & & & & & & $\begin{array}{c}0.356 \\
(0.455)\end{array}$ \\
\hline VeryWarmCountry $\times$ Earthquake & & & & & & $\begin{array}{l}-0.125 \\
(0.739)\end{array}$ \\
\hline Precipitation & $\begin{array}{c}-0.964 \\
(1.740)\end{array}$ & $\begin{array}{c}-0.904 \\
(1.726)\end{array}$ & $\begin{array}{l}-1.317 \\
(1.665)\end{array}$ & $\begin{array}{l}-0.870 \\
(1.791)\end{array}$ & $\begin{array}{l}-1.133 \\
(1.728)\end{array}$ & $\begin{array}{c}-0.855 \\
(1.714)\end{array}$ \\
\hline Observations & 1,350 & 1,350 & 1,350 & 1,350 & 1,350 & 1,350 \\
\hline R-squared & 0.382 & 0.383 & 0.383 & 0.381 & 0.382 & 0.381 \\
\hline Country FE & Yes & Yes & Yes & Yes & Yes & Yes \\
\hline Region $\times$ Year FE & Yes & Yes & Yes & Yes & Yes & Yes \\
\hline
\end{tabular}

This table shows robustness checks for the potential underlying channels of the temperature-sovereign risk connection. $\triangle \mathrm{GDP}$ is quarterly GDP growth, aggregated at the yearly level. Drought, DroughtDamage (droughts with a damage report) Wildfire, Flood, Storm and Earthquake are monthly dummies indicating the corresponding natural disaster, which are also aggregated on the yearly level. VeryWarmCountry is a dummy for the countries in the warmest country group, see Table 5. Standard errors (in parentheses) are clustered at the country level, ${ }^{* * *},{ }^{* *}$ and $*$ indicate statistical significance at the $1 \%, 5 \%$ and $10 \%$ level, respectively. See Table 18 for variable definitions and sources. 
Table 17: Robustness tests: impact of natural disasters on political stability

\begin{tabular}{|c|c|c|c|c|c|c|}
\hline & $\begin{array}{c}\text { (1) } \\
\text { Political } \\
\text { Stability }\end{array}$ & $\begin{array}{c}\quad(2) \\
\text { Political } \\
\text { Stability }\end{array}$ & $\begin{array}{c}\text { (3) } \\
\text { Political } \\
\text { Stability }\end{array}$ & $\begin{array}{c}\quad(4) \\
\text { Political } \\
\text { Stability }\end{array}$ & $\begin{array}{c}\quad(5) \\
\text { Political } \\
\text { Stability }\end{array}$ & $\begin{array}{c}\quad(6) \\
\text { Political } \\
\text { Stability }\end{array}$ \\
\hline Drought & $\begin{array}{l}-1.317 \\
(1.488)\end{array}$ & & & & & \\
\hline VeryWarmCountry $\times$ Drought & $\begin{array}{l}-3.221 \\
(2.954)\end{array}$ & & & & & \\
\hline DroughtDamage & & $\begin{array}{l}-1.083 \\
(1.762)\end{array}$ & & & & \\
\hline VeryWarmCountry $\times$ DroughtDamage & & $\begin{array}{c}-7.257^{* * *} \\
(2.332)\end{array}$ & & & & \\
\hline Wildfire & & & $\begin{array}{r}-9.970^{*} \\
(5.942)\end{array}$ & & & \\
\hline VeryWarmCountry $\times$ Wildfire & & & $\begin{array}{l}-12.42 \\
(9.729)\end{array}$ & & & \\
\hline Flood & & & & $\begin{array}{c}11.29^{* * *} \\
(3.842)\end{array}$ & & \\
\hline VeryWarmCountry $\times$ Flood & & & & $\begin{array}{l}-6.798 \\
(8.455)\end{array}$ & & \\
\hline Storm & & & & & $\begin{array}{l}-0.379 \\
(4.425)\end{array}$ & \\
\hline VeryWarmCountry $\times$ Storm & & & & & $\begin{array}{l}-6.055 \\
(8.951)\end{array}$ & \\
\hline Earthquake & & & & & & $\begin{array}{c}-10.68^{* *} \\
(4.575)\end{array}$ \\
\hline VeryWarmCountry $\times$ Earthquake & & & & & & $\begin{array}{c}1.244 \\
(10.25)\end{array}$ \\
\hline Precipitation & $\begin{array}{l}-4.542 \\
(17.91)\end{array}$ & $\begin{array}{l}-4.206 \\
(17.82)\end{array}$ & $\begin{array}{l}-6.167 \\
(18.55)\end{array}$ & $\begin{array}{l}-15.35 \\
(17.13)\end{array}$ & $\begin{array}{l}-0.207 \\
(17.25)\end{array}$ & $\begin{array}{l}-0.432 \\
(18.01)\end{array}$ \\
\hline Observations & 1,242 & 1,242 & 1,242 & 1,242 & 1,242 & 1,242 \\
\hline R-squared & 0.888 & 0.889 & 0.888 & 0.890 & 0.888 & 0.888 \\
\hline Country FE & Yes & Yes & Yes & Yes & Yes & Yes \\
\hline Region $\times$ Year FE & Yes & Yes & Yes & Yes & Yes & Yes \\
\hline
\end{tabular}

This table shows robustness checks for the potential underlying channels of the temperature-sovereign risk connection. Political Stability is the corresponding World Bank Score, ranging from 0 to 100. Drought, DroughtDamage (droughts with a damage report) Wildfire, Flood, Storm and Earthquake are monthly dummies indicating the corresponding natural disaster, which are aggregated on the yearly level. VeryWarmCountry is a dummy for the countries in the warmest country group, see Table 5. Standard errors (in parentheses) are clustered at the country level, $*^{* *},{ }^{* *}$ and $*$ indicate statistical significance at the $1 \%, 5 \%$ and $10 \%$ level, respectively. See Table 18 for variable definitions and sources. 


\section{Appendix}

Table 18: Description and sources of variables

Variable

Description

Source

Variables in Baseline Regression (Section 4)

\begin{tabular}{|c|c|c|}
\hline$\Delta \mathrm{EMBI}$ & $\begin{array}{l}\text { Monthly change in natural logarithm of Emerging Market } \\
\text { Bond Index (Global) (winsorized at 1st and 99th percentile) }\end{array}$ & J.P. Morgan \\
\hline $\begin{array}{l}\text { Historical Temperature } \\
\text { Anomaly } \\
\text { (HistoricalTempAnomaly) }\end{array}$ & $\begin{array}{l}\text { Difference between monthly temperature of a country and } \\
\text { its 1901-1950 temperature average of the same month }\end{array}$ & $\begin{array}{l}\text { Climatic Research Unit } \\
\text { see Harris et al. (2020) }\end{array}$ \\
\hline $\begin{array}{l}\text { Deviation-Adjusted } \\
\text { Temperature Anomaly } \\
\text { (DeviationAdjusted- } \\
\text { TempAnomaly) }\end{array}$ & $\begin{array}{l}\text { HistoricalTempAnomaly divided by a country's 1901-1950 } \\
\text { standard deviation of monthly temperature }\end{array}$ & $\begin{array}{l}\text { Climatic Research Unit } \\
\text { see Harris et al. (2020) }\end{array}$ \\
\hline Precipitation & Precipitation in units of $1000 \mathrm{~mm}$ per month & $\begin{array}{l}\text { Climatic Research Unit } \\
\text { see Harris et al. (2020) }\end{array}$ \\
\hline$\Delta \mathrm{VIX}$ & $\begin{array}{l}\text { Monthly first difference in VIX volatility index } \\
\text { (winsorized at 1st and } 99 \text { th percentile) }\end{array}$ & $\mathrm{CBOE}$ \\
\hline$\Delta$ US-CorporateRiskPremium & $\begin{array}{l}\text { Monthly first difference in spread between the S\&P US high } \\
\text { yield corporate bond index and the corresponding investment } \\
\text { grade index (winsorized at 1st and 99th percentile) }\end{array}$ & $\mathrm{S} \& \mathrm{P}$ \\
\hline$\Delta$ US-10-YearTreasuryYield & $\begin{array}{l}\text { Monthly first difference in the yield of the } 10 \text {-year US } \\
\text { Treasury bond (winsorized at 1st and 99th percentile) }\end{array}$ & Datastream \\
\hline$\Delta$ US-TermSpread & $\begin{array}{l}\text { Monthly first difference in spread between } 10 \text {-year US } \\
\text { Treasury yield and } 3 \text {-month US T-Bill yield (winsorized } \\
\text { at } 1 \text { st and } 99 \text { th percentile) }\end{array}$ & $\begin{array}{l}\text { Datastream, } \\
\text { Federal Reserve }\end{array}$ \\
\hline $\begin{array}{l}\Delta \text { GlobalGovernment } \\
\text { BondIndex }\end{array}$ & $\begin{array}{l}\text { Monthly change in natural logarithm of Bank Of America } \\
\text { Merrill Lynch Global Government Index (winsorized at 1st } \\
\text { and 99th percentile) }\end{array}$ & Merrill Lynch \\
\hline
\end{tabular}

Variables in Interaction and Bin Regressions (Section 5)

$\begin{array}{ll}\text { Very cold, cold, mild, warm, } & \begin{array}{l}\text { Countries are grouped into a bin according to percentile } \\ \text { very warm country }\end{array} \\ \text { distribution of average annual temperature (1901-2018), } \\ \text { (percentile) }\end{array}$

Very cold, cold, mild, warm, Countries are grouped into a bin according to $5^{\circ} \mathrm{C}$ - intervals

very warm country $\quad \leq 10^{\circ} \mathrm{C}$ (very cold), $>10 \& \leq 15^{\circ} \mathrm{C}$ (cold), $>15 \& \leq 20^{\circ} \mathrm{C}$

$\left(5^{\circ} \mathrm{C}\right.$ - interval) $\quad$ (mild),$>20 \& \leq 25^{\circ} \mathrm{C}$ (warm),$>25^{\circ} \mathrm{C}$ (very warm)

\begin{tabular}{lll}
\hline Agriculture to GDP & Value added of agriculture (\% of gross domestic product) & World Bank \\
\hline Manufacturing to GDP & Value added of manufacturing (\% of gross domestic product) & World Bank \\
\hline Services to GDP & Value added of services (\% of gross domestic product) & World Bank \\
\hline Resource Rents to GDP & $\begin{array}{l}\text { Sum of oil rents, natural gas rents, coal rents (hard and soft), } \\
\text { mineral rents, and forest rents (\% of gross domestic product) }\end{array}$ & \\
\hline
\end{tabular}

Rule of law rank (the extend of which agents have confidence in and abide by the rules of society; linearly interpolated) World Bank

Control of corruption rank (the extent to which public power is exercised for private gain, including both petty and grand forms of corruption, as well as "capture" of the

World Bank

Control of Corruption state by elites and private interests; linearly interpolated) 
Civil Liberties

\begin{tabular}{|c|c|c|}
\hline Political Rights & $\begin{array}{l}\text { Countries and territories with a rating of } 1 \text { enjoy a wide } \\
\text { range of political rights, including free and fair elections. } \\
\text { Countries and territories with a rating of } 7 \text { have few or } \\
\text { no political rights }\end{array}$ & Freedom House \\
\hline ND-GAIN & $\begin{array}{l}\text { Notre Dame Global Adaption Index; ND-GAIN brings } \\
\text { together over } 74 \text { variables to form } 45 \text { core indicators to } \\
\text { measure vulnerability and readiness to climate change }\end{array}$ & $\begin{array}{l}\text { Notre Dame Global } \\
\text { Adaption Initiative }\end{array}$ \\
\hline Readiness Index & $\begin{array}{l}\text { Readiness component of ND-GAIN; measures readiness } \\
\text { by considering a country's ability to leverage investments } \\
\text { to climate adaptation actions }\end{array}$ & $\begin{array}{l}\text { Notre Dame Global } \\
\text { Adaption Initiative }\end{array}$ \\
\hline Vulnerability Index & $\begin{array}{l}\text { Vulnerability component of ND-GAIN; measures propensity } \\
\text { or predisposition of human societies to be negatively } \\
\text { impacted by climate hazards }\end{array}$ & $\begin{array}{l}\text { Notre Dame Global } \\
\text { Adaption Initiative }\end{array}$ \\
\hline GDP per Capita & $\begin{array}{l}\text { Gross domestic product per capita in constant } \\
2010 \text {-US-dollar prices }\end{array}$ & World Bank \\
\hline
\end{tabular}

Variables in Robustness Tests (Section 6)

\begin{tabular}{lll}
\hline$\Delta$ EMBI Spread & $\begin{array}{l}\text { Monthly first difference in Emerging Market Bond Spread } \\
\text { (Global) (winsorized at 1st and 99th percentile) }\end{array}$ & J.P. Morgan \\
\hline$\Delta$ CDS Spread & $\begin{array}{l}\text { Monthly first difference in sovereign CDS Spread } \\
\text { (winsorized at 1st and 99th percentile) }\end{array}$ & $\begin{array}{l}\text { Thomson Reuters } \\
\text { CDS }\end{array}$ \\
\hline \multirow{2}{*}{ Political Stability } & $\begin{array}{l}\text { Political stability and absence of violence rank (likelihood of } \\
\text { political instability and/or politically motivated violence, } \\
\text { including terrorism; linearly interpolated) }\end{array}$ & World Bank \\
\hline \hline
\end{tabular}

Variables in Robustness Tests (Section 7)

\begin{tabular}{lll}
\hline Natural Disasters & $\begin{array}{l}\text { Date of drought, earthquake, epidemic, heat wave, flood, } \\
\text { impact, insect infestation, landslide, mass movement, storm, } \\
\text { volcanic activity, wildfire (total deaths, damage and affected } \\
\text { people for certain disasters) }\end{array}$ & $\begin{array}{l}\text { International Disaster } \\
\text { Database }\end{array}$ \\
\hline GDP Growth & $\begin{array}{l}\text { Quarterly natural log change of GDP in constant, } \\
\text { seasonally-adjusted 2015 US-Dollar prices }\end{array}$ & Oxford Economics \\
\hline Post Paris & Dummy that is 1 after Paris Agreement (December 2015) & \\
\hline \hline Further data used & Natural log returns of stock market index & MSCI, S\&P \\
\hline Stock Returns & Accumulated CO ${ }_{2}$ emissions of every country and the & IMF Fiscal Monitor \\
\hline Government Primary Surplus Government primary net lending/borrowing (\% of GDP) & $\begin{array}{l}\text { Getrieved via } \\
\text { ourworldindata.org }\end{array}$ \\
\hline Accumulated $\mathrm{CO}_{2}$ & Total population of every country and the world in 2017 & World Bank \\
\hline Emissions & &
\end{tabular}




\section{Declarations}

\section{Availability of data and materials}

All data used during the current study is publicly available. The dataset and the results are therefore fully replicable. All data sources and variable definitions are listed in detail in Table 18. Datasets can be provided by the author if requested.

\section{Competing interests}

The author declares that he has no competing interests.

\section{Funding}

There was no outside funding of the current study. The paper was written as part of the standard employment relationship of the author with the Halle Institute for Economic Research (IWH).

\section{Authors' contributions}

Not applicable as the paper is single-authored.

\section{Acknowledgments}

The author is grateful for all the advice for this project, in particular from Stefan Eichler, Felix Noth, Thomas Krause, Ingmar Roevekamp, Christoph Schult, Gregor von Schweinitz, Lena Tonzer and Konstantin Wagner. Special thanks goes to Michael Barkholz for helping on temperature data and Mikael Homanen's literature review on ESG \& finance. 